\title{
High-Resolution Gridded Daily Rainfall and Temperature for the Hawaiian Islands (1990-2014)
}

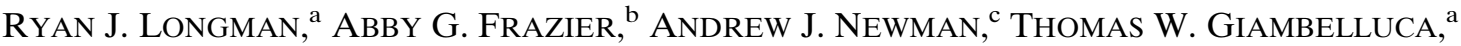 \\ David SCHANZENBACH, ${ }^{\mathrm{d}}$ Aurora Kagawa-Viviani, ${ }^{\mathrm{a}}$ Heidi NeEdHam, ${ }^{\mathrm{a}}$ \\ JEFFREY R ARNOLD, ${ }^{\mathrm{e}}$ AND MARTYN P. CLARK ${ }^{\mathrm{c}}$ \\ ${ }^{a}$ Department of Geography and Environment, University of Hawai' $i$ at Mānoa, Honolulu, Hawaii \\ ${ }^{\mathrm{b}}$ East-West Center, Honolulu, Hawaii \\ ${ }^{\mathrm{c}}$ National Center for Atmospheric Research, Boulder, Colorado \\ ${ }^{\mathrm{d}}$ Information Technology Services, University of Hawai' $i$ at Mānoa, Honolulu, Hawaii \\ ${ }^{\mathrm{e}}$ Climate Preparedness and Resilience Program, U.S. Army Corps of Engineers, Seattle, Washington
}

(Manuscript received 31 May 2018, in final form 15 January 2019)

\begin{abstract}
Spatially continuous data products are essential for a number of applications including climate and hydrologic modeling, weather prediction, and water resource management. In this work, a distance-weighted interpolation method used to map daily rainfall and temperature in Hawaii is described and assessed. New high-resolution $(250 \mathrm{~m})$ maps were developed for daily rainfall and daily maximum $\left(T_{\max }\right)$ and minimum $\left(T_{\min }\right)$ near-surface air temperature for the period 1990-2014. Maps were produced using climatologically aided interpolation, in which station anomalies were interpolated using an optimized inverse distance weighting approach and then combined with long-term means to produce daily gridded estimates. Leave-oneout cross validation was performed to assess the quality of the final daily grids. The median absolute prediction error for rainfall was $0.1 \mathrm{~mm}$ with an average overprediction $(+0.6 \mathrm{~mm})$ on days when total rainfall was less than $1 \mathrm{~mm}$. On days with total rainfall greater than $1 \mathrm{~mm}$, median absolute prediction errors were $2 \mathrm{~mm}$ and rainfall was typically underpredicted above the $10-\mathrm{mm}$ threshold. For daily temperature, median absolute prediction errors were $3.1^{\circ}$ and $2.8^{\circ} \mathrm{C}$ for $T_{\max }$ and $T_{\min }$, respectively. On average, this method overpredicted $T_{\max }\left(+1.1^{\circ} \mathrm{C}\right)$ and $T_{\min }\left(+1.5^{\circ} \mathrm{C}\right)$, and errors varied considerably among stations. Errors for all variables exhibited significant seasonal variations. However, the annual range of errors was small. The methods presented here provide an effective approach for mapping daily weather fields in a topographically diverse region and improve on previous products in their spatial resolution, time period of coverage, and use of data.
\end{abstract}

\section{Introduction}

Gridded climate data are useful for a number of applications such as decision-making in environmental management, climate and hydrologic modeling, risk assessment, and water resource planning where knowledge of the spatial distributions are important. However, gridded data are often not readily available and can be difficult to develop, especially for mountainous regions ( $\mathrm{Li}$ and Heap 2008) and at fine spatial (e.g., $250 \mathrm{~m}$ ) and temporal (e.g., hourly/daily) resolutions. Gridded datasets are often derived from point measurements which are typically sparse in mountainous regions where access is limited. Even in areas where observation networks are

Corresponding author: Ryan J. Longman, rlongman@hawaii.edu dense, complex topographic and climatic features can make the development of realistic gridded fields hard to achieve.

In Hawaii, much effort has been expended to improve the quality of existing climate data (Giambelluca et al. 2013; Longman et al. 2018, hereafter L18) and a number of gridded climate products at various temporal resolutions are available that leverage this work. Giambelluca et al. (2013) developed climatological rainfall maps at a 250-m spatial resolution for seven of the main islands in Hawaii (http://rainfall.geography.hawaii.edu/). This product makes use of average spatial patterns derived for a 30 -yr period using a Bayesian data fusion method to combine rain gauge data with radar rainfall estimates, mesoscale meteorological model (MM5) output, and Parameter-Elevation Regressions on Independent 
Slopes Model (PRISM) maps (Daly et al. 1994). Daly et al. (2006) developed 30-yr mean (1971-2000) precipitation and temperature fields (12 mean monthly maps and 1 annual map for each variable), and Frazier et al. (2016) developed month-year rainfall maps for the period 1920-2012. Gridded climatologies of other climate variables, such as temperature, relative humidity, and over 40 other meteorological variables (Giambelluca et al. 2014, hereafter G14), were developed on the same 250-m grid used by Giambelluca et al. (2013). Limited effort has been undertaken to develop daily gridded fields, which are key to impact modeling work. Recently, Daymet (version 3) was extended to cover Hawaii at a $1-\mathrm{km}$ spatial resolution from 1980 to 2008 using only data available through public electronic data repositories (see Thornton et al. 2012). Here we continue to leverage an extensive observational network (see L18) compiled for Hawaii to develop daily gridded estimates of rainfall and temperature at 250-m resolution for the period 1990-2014.

The availability of gridded daily rainfall and temperature maps at a fine spatial resolution fulfills a critical need in the research community in Hawaii. With spectacular topographically induced gradients and as the most isolated island group on Earth, the Hawaiian Islands are critically reliant on knowledge of the patterns of climate for managing and protecting natural resources such as freshwater and the islands' unique ecosystems. Management decisions benefit greatly from high-resolution datasets, necessary to adequately capture the extreme spatial variability of climate. Hawaii's ecosystems are characterized by high endemism and a high percentage of threatened and endangered species vulnerable to climate change and invasion by nonnative species. Stakeholders, including resource managers and decision-makers, are constrained by the data available to them, making higher temporal and spatial resolution data a critical need.

This current endeavor builds on a long history of mapping rainfall in Hawaii and improves on previous products in its spatial resolution, time period of coverage, and the inclusion of new observation stations. In addition, this work provides a foundation on which more sophisticated methods for mapping climate variables at similar spatial and temporal resolutions can be developed. Note that precipitation in Hawaii consists of rainfall, different types of frozen precipitation (e.g., snow, sleet, hail, and freezing rain), and fog drip (Giambelluca et al. 2013). Following L18, the term rainfall is used throughout the paper to describe all forms of precipitation measured in rain gauges in Hawaii.

A variety of different methods for the spatial interpolation of environmental point data exist, and the choice of method depends on a number of factors ( $\mathrm{Li}$ and Heap
2008). Examples include linear regression (e.g., Di Piazza et al. 2011; Clark and Slater 2006; Camera et al. 2014; Newman et al. 2015), geographically weighted regression (Di Piazza et al. 2011), splines (e.g., Hofstra et al. 2008), Thiessen polygons (e.g., Wagner et al. 2012), inverse distance weighting (IDW; e.g., Camera et al. 2014), angular distance weighting (e.g., Hofstra et al. 2008), nearest neighbor (e.g., Shen et al. 2001), artificial neural networks (e.g., Di Piazza et al. 2011), or various types of kriging (e.g., Brinckmann et al. 2016; Di Piazza et al. 2011; Frazier et al. 2016).

The most appropriate interpolation method for gridded point estimates varies as a function of the area, the spatial and temporal scales desired (Vicente-Serrano et al. 2003), and the availability of data. For example, kriging has been commonly used for spatial interpolation of both rainfall and temperature at various spatial scales and temporal resolutions (e.g., Hattermann et al. 2005; Buytaert et al. 2006; Berezowski et al. 2016; Brinckmann et al. 2016; Frazier et al. 2016), but requires a significant amount of point data to achieve accurate results. To quantify the distance dependency of spatial autocorrelation in the form of an empirical semivariogram, as required in kriging, at least 100 measurement pairs (ideally 150) are needed (Webster and Oliver 2001). In data scarce regions, simple interpolation approaches such as IDW are commonly employed (e.g., Teegavarapu and Chandramouli 2005; Croke et al. 2011; Di Piazza et al. 2011). In general, the most accurate interpolation results are found in regions with high observation density and low topographic complexity (Brinckmann et al. 2016).

In mountainous regions, spatial rainfall patterns are influenced by the irregular topography, thus making the interpolation of daily rainfall intrinsically difficult (Jeffrey et al. 2001). In addition, due to the stochastic nature of daily rainfall, large variability in elevation, slope, and aspect terms on the landscape of Hawaii increases spatial variability due to orographic processes, rain shadow effects, and strong winds (Buytaert et al. 2006). In complex topography, kriging or other geostatistical methods used to interpolate rainfall can produce unreliable results due to extreme spatial variability (Shen et al. 2001) especially at a daily time step or when data are sparse. In Hawaii, ordinary kriging was shown to be effective over complex topography for mapping rainfall at a monthly time scale (Mair and Fares 2011; Frazier et al. 2016). Due to the complex topography found in Hawaii and the limited number of observations available at the daily time step, we have chosen to adopt the simple IDW approach for the interpolation of both rainfall and temperature in this analysis.

In combination with the IDW approach, we use a climatologically aided interpolation (CAI; Willmott and 
Robeson 1995) method, which combines long-term climate information with daily station data to develop the daily gridded estimates. This allows for information propagation from the climatological patterns, based on a denser climatological station network, through to the daily fields. With CAI, departures from the mean (anomalies) on a given month (or day) are interpolated and then combined with a mean map to produce the final monthly (or daily) map (e.g., Dawdy and Langbein 1960; Willmott and Robeson 1995; Frazier et al. 2016). In Hawaii, the climatological network is much denser than the daily observation network and more completely resolves the steep rainfall gradients associated with orographic processes (e.g., Giambelluca et al. 2013; Frazier et al. 2016; L18).

The CAI approach has been shown to produce better results than interpolating absolute rainfall values at a regional scale (New et al. 2000; Chen et al. 2002) and has been used in a number of studies for the interpolation of rainfall and temperature (Dawdy and Langbein 1960; Willmott and Robeson 1995; Haylock et al. 2008; Frazier et al. 2016). The CAI approach has been shown to be especially effective at improving the prediction accuracy for both rainfall and temperature interpolation in regions of variable terrain with limited observations (e.g., Hunter and Meentemeyer 2005). The main advantage of the CAI approach is that climatology maps have more spatial information built into them because they are derived from a denser network of weather stations.

The objective of this study is to produce daily rainfall, and maximum $\left(T_{\max }\right)$ and minimum $\left(T_{\min }\right)$ near-surface air temperature maps at a high spatial resolution $(250 \mathrm{~m})$ for the state of Hawaii for a 25-yr period (1990-2014), and to quantify the spatially-dependent uncertainty in the interpolated fields.

\section{Study area and data}

The study area encompasses seven main Hawaiian Islands including, Hawaii Island, Maui, Kahoolawe, Lanai, Molokai, Oahu, and Kauai. Hawaii has some of the most diverse rainfall patterns on Earth due to the combination of persistent winds, a large elevation range (0-4205 m), complex mountainous topography, and an atmospheric inversion. Combined with elevation dependent changes in temperature, these diverse features produce nearly all commonly encountered climate zones across the complete island chain. The majority of rainfall is produced as a result of moist marine air being orographically lifted up along windward mountain slopes by persistent east-northeast trade winds (Leopold 1949; Sanderson 1993; Garza et al. 2012; Giambelluca et al. 2013). At high elevations, the vertical development of clouds is capped by an atmospheric trade wind inversion (TWI), which has an annual mean base height of $\sim 2150 \mathrm{~m}$ and results in dry atmospheric conditions above (Longman et al. 2015). Trade wind orographic rainfall is the most prevalent synoptic weather pattern in Hawaii, however, significant contributions to the total precipitation and extreme rainfall events in Hawaii have been linked synoptic disturbances such as cold fronts, kona storms (low pressure systems that develop to the surface and are cut off from midlatitude westerly flow), upper-tropospheric disturbances, and tropical systems (Kodama and Barnes 1997).

The spatial pattern of surface air temperature across the Hawaiian Islands is largely dependent on elevation through adiabatic cooling and warming of rising and sinking air, respectively, and exchanges of latent heat associated with the evaporation and formation of cloud droplets (Giambelluca et al. 2014). Within the TWI layer, however, temperature increases with elevation. Because of day-to-day vertical shifts in the TWI height and thickness, the inversion cannot be seen in the profile when averaged over multiple days. However, the mean surface lapse rates differ for zones below and above the mean TWI base height (Giambelluca et al. 2014). Windward-leeward differences in surface lapse rates (Minder et al. 2010) driven by differences in local surface energy balance and atmospheric conditions are also important.

In this study, we follow regression methods presented in G14 to create a new set of mean monthly temperature maps based on an updated temperature dataset (see L18). We chose to develop new maps rather than use the existing G14 temperature maps because the availability of the L18 dataset, which 1) draws from more stations, including 13 additional high-elevation stations, 2) covers a more recent and uniform base period (19902014) than was used previously, and 3) was subjected to more rigorous quality control. Furthermore, to model windward-leeward effects, G14 used mean annual rainfall grids (Giambelluca et al. 1986) that have since been updated (Giambelluca et al. 2013).

The climate data used in this study cover the period 1990-2014. Data were quality controlled and gap-filled as part of a previous study (see L18). In total, daily rainfall data from 471 stations and $T_{\max }$ and $T_{\min }$ data from 142 stations were utilized (Fig. 1). The number of historical rain gauge stations available at the daily time step is considerably smaller than the number available to map monthly rainfall (over 1100 stations were used to produce the month-year maps; Frazier et al. 2016). This difference between monthly and daily station counts is caused by several factors. First, many of the historical stations in the monthly dataset were manually read accumulating gauges, and rainfall records were often not 


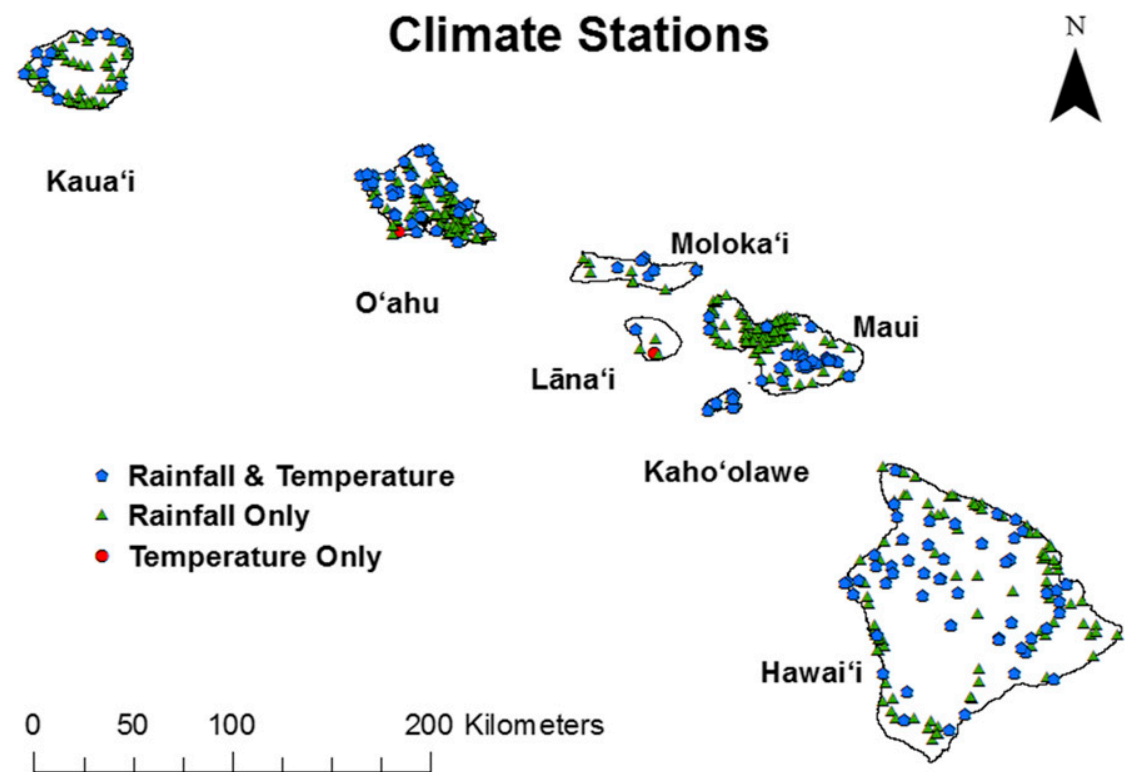

FIG. 1. Locations of all of the climate stations used in the IDW interpolation.

read on a regular daily interval (some were read only on weekdays, others were recorded weekly or even monthly, with totals representing the accumulation of rainfall since the last reading). Second, some monthly values may have been aggregated from daily data that had an incomplete time series for the month in question. Finally, Hawaii has experienced a sharp decrease in the number of operational gauges since the 1980s with the decline of plantation agriculture (Giambelluca et al. 2013). Monthly datasets utilized by Frazier et al. (2016) used station data beginning in 1920 and many of the historical (discontinued) stations were gap-filled across the period of record. Mean monthly rainfall maps were obtained from the Rainfall Atlas of Hawai'i (http://rainfall.geography.hawaii.edu/).

\section{Methods}

\section{a. Anomaly calculations}

\section{1) RAINFALL}

Rainfall relative anomalies were calculated as the ratio of a daily station observation to the mean daily value at that same location:

$$
\operatorname{RFAnom}_{x}=\frac{\mathrm{RFO}_{x}}{\operatorname{RFMean}_{x}},
$$

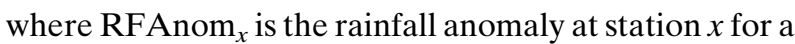
given day (e.g., 1 January 1990 anomaly), $\mathrm{RFO}_{x}$ is the observed daily rainfall at station $x$ for a given day (e.g., 1 January 1990 rainfall value), and RFMean ${ }_{x}$ is the mean daily rainfall at station $x$ for the given month (e.g., January daily mean value). For rainfall, relative anomalies are preferred over absolute anomalies because the ratio better preserves the relationship between the mean and the variance (New et al. 2000). To obtain mean daily rainfall values for each month, first, the mean monthly rainfall value corresponding to a unique station was extracted from the mean monthly map (Giambelluca et al. 2013). Next, this extracted value was divided by the number of days in a respective month to produce mean daily value. We elected to calculate each anomaly relative to the mapped mean rather than the station mean because not all of the stations had the 30 years of data necessary to derive a climatological mean.

\section{2) Temperature}

To facilitate calculation of temperature anomalies, it was necessary to create a set of mean monthly $T_{\max }$ and $T_{\min }$ maps so the CAI approach could be applied effectively. Due to the sharp discontinuity in temperature created by the TWI, a segmented linear regression technique was used to relate mean monthly station temperature data with elevation and mean annual rainfall (Giambelluca et al. 2014). First, daily station data were aggregated to monthly values, and then to mean monthly values at each station over the 1990-2014 study period. Next, to generate the maps, mean monthly station temperature data were related to elevation and mean annual rainfall using a segmented linear regression technique (Giambelluca et al. 2014). The segmented regression approach allowed for different temperature-elevation relationships in two elevation ranges to accommodate the discontinuity in the mean environmental 
temperature lapse rate due to the TWI; the lower- and upper-level regressions were separated at the approximate mean TWI level (Longman et al. 2015). A mean annual rainfall term was included to capture windwardleeward effects on cloud cover (solar radiation) and moisture availability (Minder et al. 2010; Giambelluca et al. 2014). Regression equations for low and high elevations [Eqs. (2) and (3), respectively] are as follows:

$$
\begin{aligned}
& T(z, \text { RFann })=\frac{a_{1}\left(z_{3}-z\right)+a_{2}\left(z-z_{1}\right)}{z_{3}-z_{1}}+a_{4} \text { RFann }, \\
& T(z, \text { RFann })=\frac{a_{2}\left(z_{2}-z\right)+a_{3}\left(z-z_{3}\right)}{z_{2}-z_{3}}+a_{4} \text { RFann },
\end{aligned}
$$

where $T$ refers to near-surface air temperature $\left(T_{\max }\right.$ or $\left.T_{\min },{ }^{\circ} \mathrm{C}\right), z$ is elevation above mean sea level (m), RFann is the long-term mean annual rainfall $(\mathrm{mm})$ extracted from the Rainfall Atlas of Hawai'i (Giambelluca et al. 2013), and elevation coefficients were set at $z_{1}=0 \mathrm{~m}, z_{2}=$ $4200 \mathrm{~m}$, and $z_{3}=2150 \mathrm{~m}$. The regressions were fitted using mean monthly station data from 142 stations ranging from 0 to $3400 \mathrm{~m}$ in elevation to obtain the coefficients $\left(a_{1}, a_{2}, a_{3}, a_{4}\right)$.With a gridded $(250 \mathrm{~m})$ digital elevation model and mean annual rainfall dataset (Giambelluca et al. 2013), these regression equations were used to create maps of mean $T_{\max }$ and $T_{\min }$ for each calendar month. We used mean station data to test the calibration skill of the mean monthly temperature maps.

Daily maximum and minimum temperature anomalies were calculated as the departure of a daily station observation from the newly created mean monthly maximum and minimum temperature map value at the station location:

$$
\operatorname{TaAnom}_{x}=\operatorname{TaObs}_{x}-\operatorname{TaMean}_{x},
$$

where TaAnom is either the maximum or minimum temperature anomaly at station $x$, TaObs is the observed daily maximum or minimum temperature at station $x$, and TaMean is the mean monthly maximum (or minimum) temperature at station $x$.

As a final screening step, maximum and minimum bounds were calculated for the observed portion of both anomaly datasets, and any anomalies in the gap-filled portion of the dataset exceeding these bounds were removed in order to avoid outliers generated from the gapfilling process (see L18).

\section{b. Interpolation method}

One of the oldest spatial prediction techniques is IDW interpolation (Shepard 1964). The IDW method estimates the value of a variable at each location using a linear combination of surrounding observations weighted by an inverse function of the distance between the observations and the interpolated location ( $\mathrm{Li}$ and Heap 2008):

$$
P\left(x_{0}\right)=\sum_{i=1}^{n} P\left(x_{i}\right) w_{i},
$$

where $P\left(x_{0}\right)$ is the predicted value, $P\left(x_{i}\right)$ are the observations considered in the interpolation, $n$ is the number of stations used in the interpolation, and $w_{i}$ are the weights, which are defined as

$$
w_{i}=\frac{1 / d_{i}^{\lambda}}{\sum_{i=1}^{n} 1 / d_{i}^{\lambda}},
$$

where $\lambda$ is the weighting parameter and $d_{i}$ is the distance between $x_{0}$ and $x_{i}$. The assumption of IDW is that observations close to each other on the ground will be more similar than those that are farther apart, therefore observations close to $x_{0}$ will be given greater weight in the interpolation. The selection of the weighting parameter, the number of sampled points used, and the neighborhood of influence are arbitrary (Webster and Oliver 2001).

To determine the best parameterization for the IDW equation in this study, we tested several combinations of these parameters using a subset of the data from Hawaii Island, for the rainfall variable. The best results were obtained when 1) sampled points were weighted with a 1.5 inverse distance $(\lambda=1.5)$ which provided better estimates in this study than the frequently used standard exponent of two (e.g., Shepard 1964), 2) no spatial restrictions were given for the neighborhood (i.e., the anomaly data could be drawn from anywhere on a given island), and 3) only the nearest five stations were used for the interpolation. The same parameterization scheme was applied to the temperature interpolation as well.

Rainfall and temperature anomalies were interpolated individually for Hawaii Island, Oahu, and Kauai. Following the methods of Frazier et al. (2016), anomaly data from the closely located islands of Molokai, Lanai, Maui, and Kahoolawe were treated as a single dataset for interpolation. The phrase Maui Nui (Greater Maui) is used to reference combined metadata and results derived from climate stations on these islands. By treating the islands of Maui Nui as a group, we are able to address the issues of data gaps on any one individual island. This is particularly important for the islands of Molokai, Lanai, and Kahoolawe, which have far less available data at the daily time step than the island of Maui. The minimum, maximum, and mean number of rainfall and temperature stations used in the interpolation on each island is presented in Table 1. 
TABLE 1. Minimum, maximum, and mean number of rainfall and temperature stations used in interpolation for each island and for each variable, the land area $\left(\mathrm{km}^{2}\right)$ of each island (Juvik and Juvik 1998) and minimum, maximum, and mean station densities (stations per km ${ }^{2}$ ).

\begin{tabular}{|c|c|c|c|c|c|c|c|}
\hline & Min No. of stations & Max No. of stations & Mean No. of stations & Area $\left(\mathrm{km}^{2}\right)$ & Min density & Max density & Mean density \\
\hline \multicolumn{8}{|c|}{$\mathrm{RF}$} \\
\hline Hawaii Island & 37 & 122 & 82 & 10433.1 & 0.004 & 0.012 & 0.008 \\
\hline Maui Nui & 28 & 137 & 109 & 3036.7 & 0.009 & 0.045 & 0.036 \\
\hline Oahu & 31 & 108 & 85 & 1546.5 & 0.020 & 0.070 & 0.055 \\
\hline Kauai & 5 & 54 & 37 & 1430.5 & 0.003 & 0.038 & 0.026 \\
\hline \multicolumn{8}{|c|}{$T_{\max }$} \\
\hline Hawaii Island & 9 & 48 & 28 & 10433.1 & 0.001 & 0.005 & 0.003 \\
\hline Maui Nui & 7 & 44 & 33 & 3036.7 & 0.002 & 0.014 & 0.011 \\
\hline Oahu & 5 & 29 & 19 & 4546.5 & 0.003 & 0.019 & 0.012 \\
\hline Kauai & 1 & 13 & 7 & 1430.5 & 0.001 & 0.009 & 0.005 \\
\hline \multicolumn{8}{|c|}{$T_{\min }$} \\
\hline Hawaii Island & 10 & 50 & 33 & 10433.1 & 0.001 & 0.005 & 0.003 \\
\hline Maui Nui & 11 & 41 & 32 & 3036.7 & 0.004 & 0.014 & 0.011 \\
\hline Oahu & 8 & 29 & 22 & 1546.5 & 0.005 & 0.019 & 0.014 \\
\hline Kauai & 2 & 13 & 8 & 1430.5 & 0.001 & 0.009 & 0.006 \\
\hline
\end{tabular}

\section{c. Final rainfall and temperature maps}

Our CAI approach consists of the following steps. First, rainfall anomalies were calculated as the ratio of station rainfall on given day to mean daily rainfall at the same location [Eq. (1)]. Next, rainfall anomalies were interpolated across a gridded field using an optimized IDW interpolation method [Eq. (5)] to create rainfall anomaly maps. Finally, values from the interpolated gridded rainfall anomaly maps were multiplied by values from the gridded mean daily rainfall maps to produce gridded daily rainfall values [Eq. (7)]:

$$
\text { RFDaily }_{z}=\text { RFAnom }_{z} \times \text { RFMean }_{m},
$$

where RFDaily is the gridded daily rainfall on a given day $z, \mathrm{RFAnom}$ is the interpolated rainfall anomaly on a given day $z$, and RFMean is the mean daily rainfall for the respective calendar month $m$ that day $z$ falls within.

For both $T_{\max }$ and $T_{\min }$, the CAI consists of the following steps. First, temperature anomalies were calculated as the departure of station data on given day from a mean ( $T_{\max }$ or $\left.T_{\min }\right)$ map value at same location [Eq. (4)]. Next, temperature anomalies were interpolated across a gridded field using an optimized IDW interpolation method [Eq. (5)] to create $T_{\max }$ and $T_{\min }$ anomaly maps. Finally, the interpolated gridded $T_{\max }$ and $T_{\min }$ anomaly map values were added to gridded mean daily $T_{\max }$ and $T_{\min }$ maps [Eq. (8)] to derive a gridded daily $T_{\max }$ and $T_{\min }$ values:

$$
\text { TaDaily }_{z}=\text { TaAnom }_{z}+\text { TaMean }_{m},
$$

where TaDaily is the gridded daily temperature $\left(T_{\max }\right.$ or $\left.T_{\min }\right)$ on a given day $z$, TaAnom is the interpolated temperature $\left(T_{\max }\right.$ or $\left.T_{\min }\right)$ anomaly on a given day $z$, and TaMean is the mean daily temperature $\left(T_{\max }\right.$ or $\left.T_{\min }\right)$ for the respective calendar month $m$ within which day $z$ falls. Once all of the gridded surfaces were created, a final check was done to ensure that $T_{\max }$ was always greater than $T_{\min }$. To avoid instances where, $T_{\max }<T_{\min }$, an alternative approach would be to interpolate $T_{\text {mean }}$ and diurnal range so that this check is no longer required. This alternative approach has been used in other work (e.g., Newman et al. 2015, 2019a), however, direct comparisons between the methods have not been performed in any of these studies.

\section{d. Cross validation}

Daily rainfall and temperature maps were tested using a leave-one-out cross-validation (LOOCV): sequentially leaving out one measured data point and reproducing it based on the information from the remaining station observations. LOOCV yields uncertainty estimates for the gridded data near each target station. LOOCV is commonly used for assessing interpolation methods (e.g., Wagner et al. 2012; Brinckmann et al. 2016), but has

TABLE 2. Mean calibration errors $\left({ }^{\circ} \mathrm{C}\right)$ for mean monthly temperature mapping.

\begin{tabular}{lccc}
\hline & MBE & MAE & RMSE \\
\hline \multicolumn{4}{c}{ All elevations } \\
$T_{\max }\left({ }^{\circ} \mathrm{C}\right)$ & 0.8 & 1.5 & \\
$T_{\min }\left({ }^{\circ} \mathrm{C}\right)$ & 0.0 & 1.4 & 1.7 \\
\multicolumn{4}{c}{ Low elevation } \\
$T_{\max }\left({ }^{\circ} \mathrm{C}\right)$ & & 1.5 \\
$T_{\min }\left({ }^{\circ} \mathrm{C}\right)$ & 0.8 & 1.5 & \\
& 0.1 & 1.6 & 1.6 \\
$T_{\max }\left({ }^{\circ} \mathrm{C}\right)$ & High elevation & & 1.6 \\
$T_{\min }\left({ }^{\circ} \mathrm{C}\right)$ & 0.6 & 1.6 & 1.8 \\
\hline
\end{tabular}




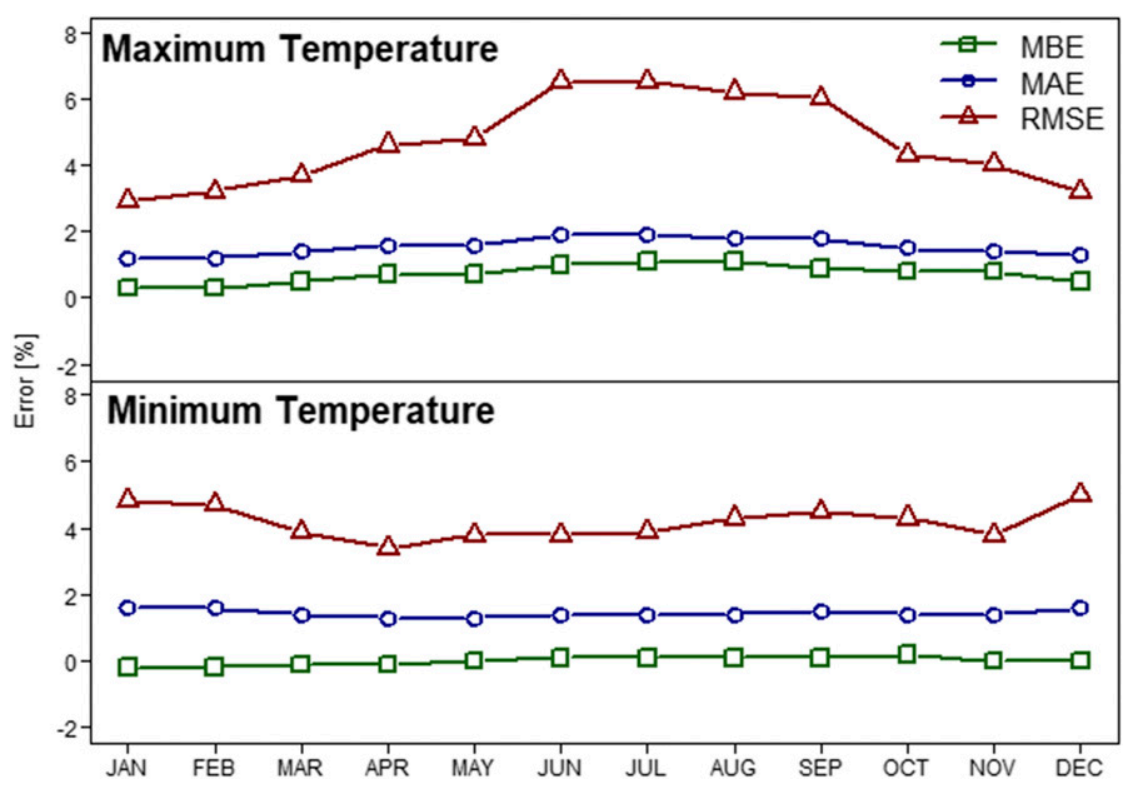

FIG. 2. Mean calibration errors for (top) mean monthly maximum temperature and (bottom) mean monthly minimum temperature at 142 locations: MBE, MAE, and RMSE.

several shortcomings that should be considered. LOOCV commonly overestimates errors at a particular location due to the fact that predictions are derived at a point where data actually exist. In addition, the interpolated surface may be altered by the removal of a point that is being cross validated (Jeffrey et al. 2001). This has the greatest impact in the areas with lowest station density.

Several skill scores are used to quantify the average interpolation skill. For rainfall we evaluate interpolation skill for different ranges of daily rainfall amounts; errors

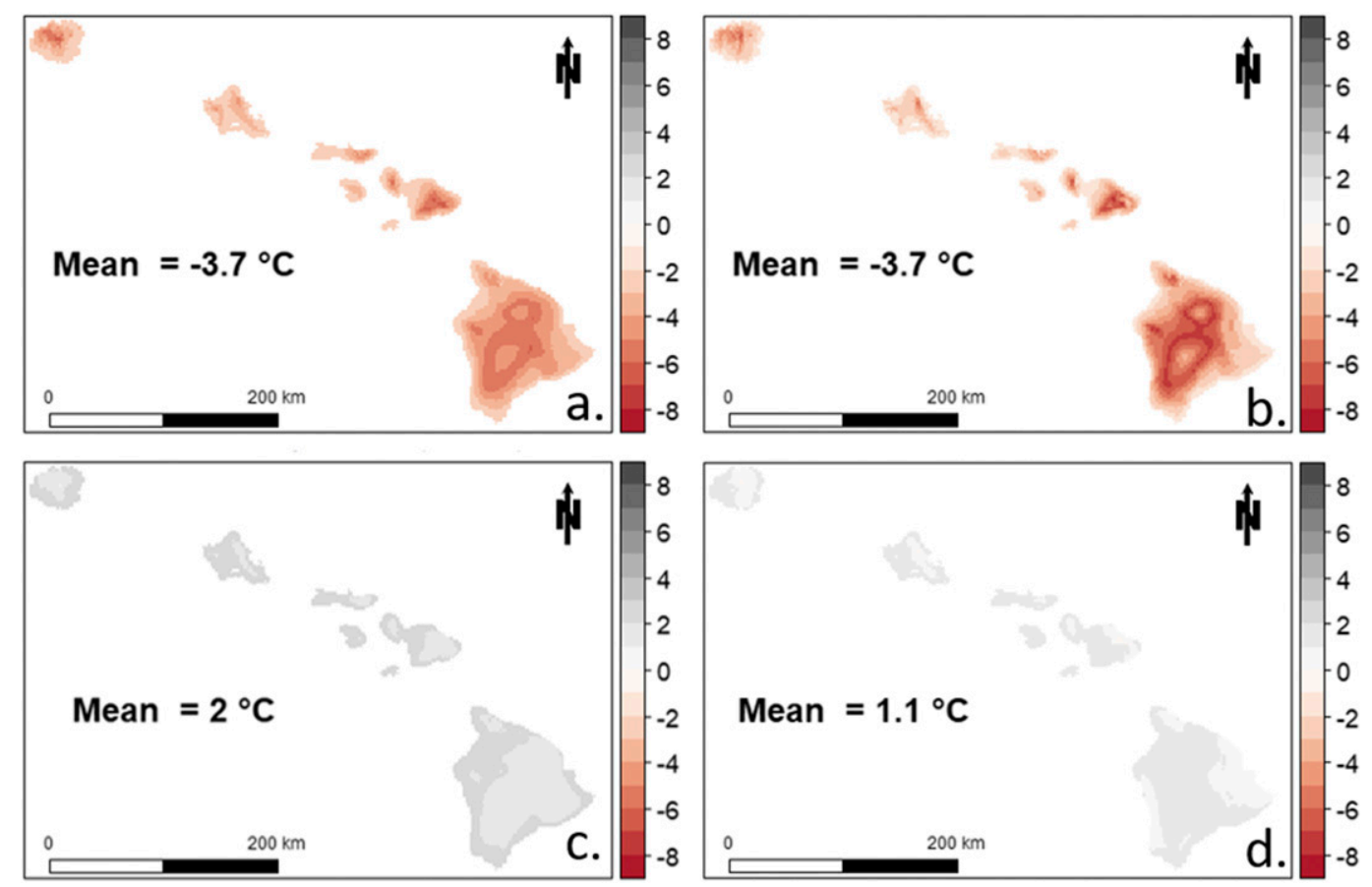

FIG. 3. Differences between G14 and L18 mean monthly (a),(b) $T_{\max }$ and (c),(d) $T_{\min }$ for temperature maps for (left) January and (right) July. Differences are calculated as G14 - L18, and the mean difference is given as the island-wide average difference between the two products. 


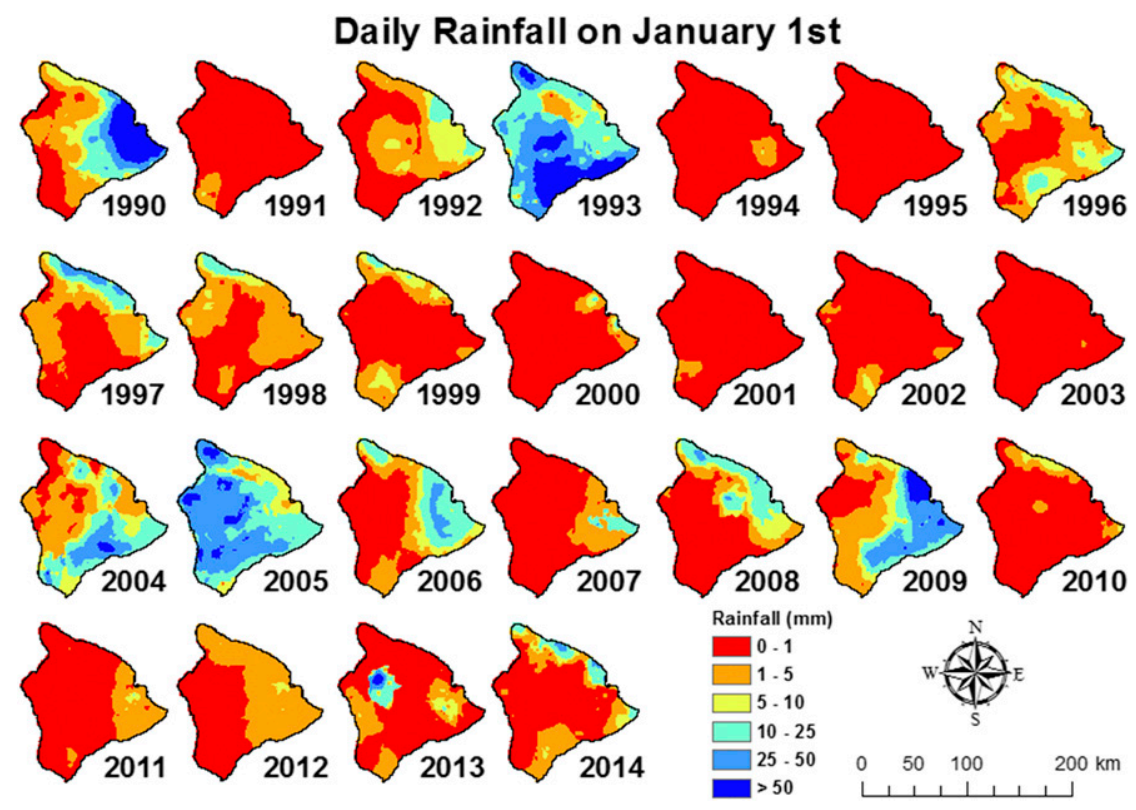

FIG. 4. Daily rainfall on 1 Jan from 1990 to 2014 for Hawaii Island.

are calculated for periods below and above a $1-\mathrm{mm}$ threshold. Prediction errors are expressed using the median (MED) of absolute differences between predicted (mapped) and observed data, and the median absolute deviation (MAD), defined as the median of the absolute deviations from the median of all data (Tukey 1977). MAD can be used as an alternative to the standard deviation in a non-normal distribution when the median is used as a measure of central tendency (Reimann et al. 2005). For the rainfall analysis, following the methods of

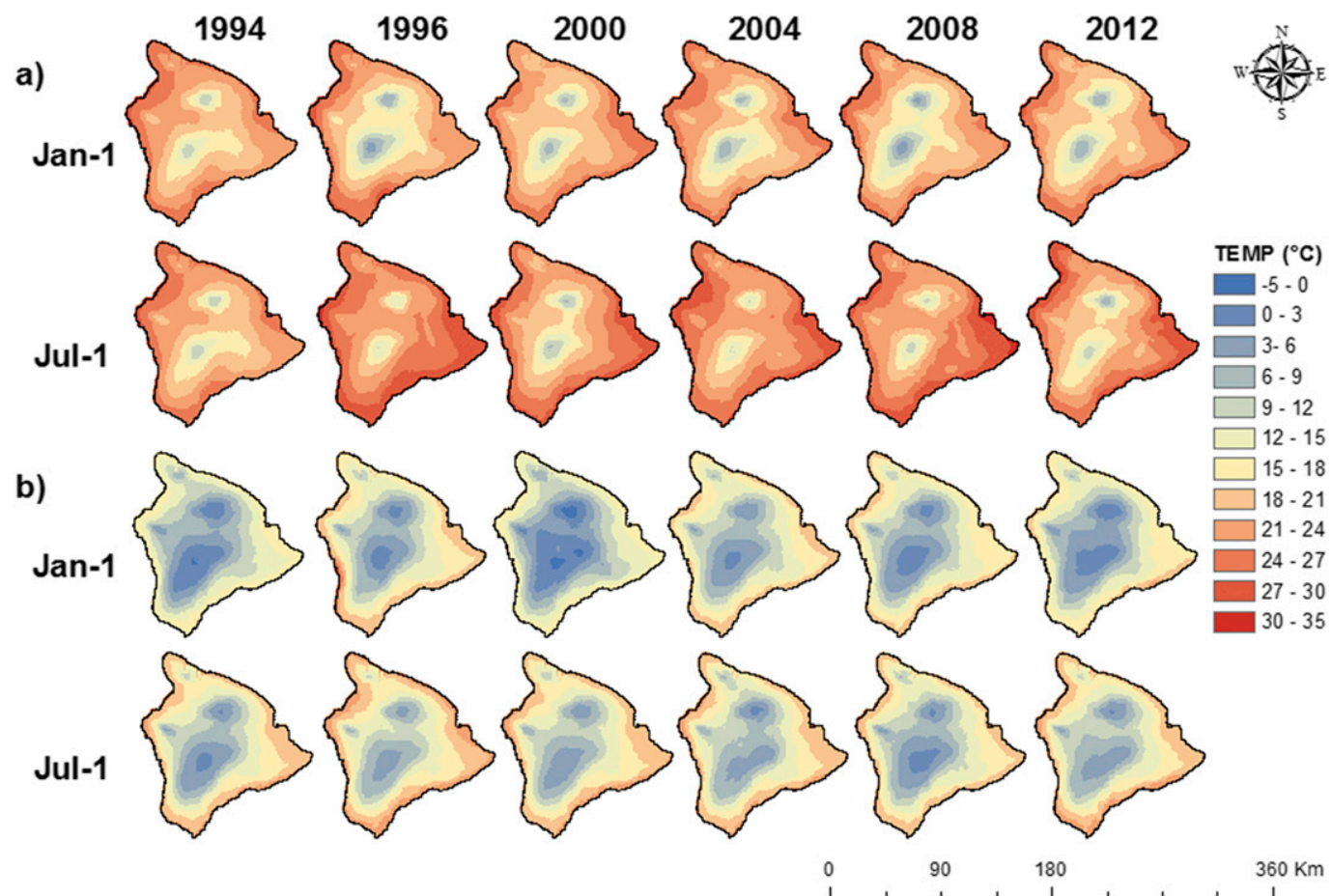

FIG. 5. (a) Daily maximum temperature and (b) daily minimum temperature for 1 Jan and 1 Jul during six unique years $(1994,1996,2000,2004,2008$, and 2012) for Hawaii Island. 

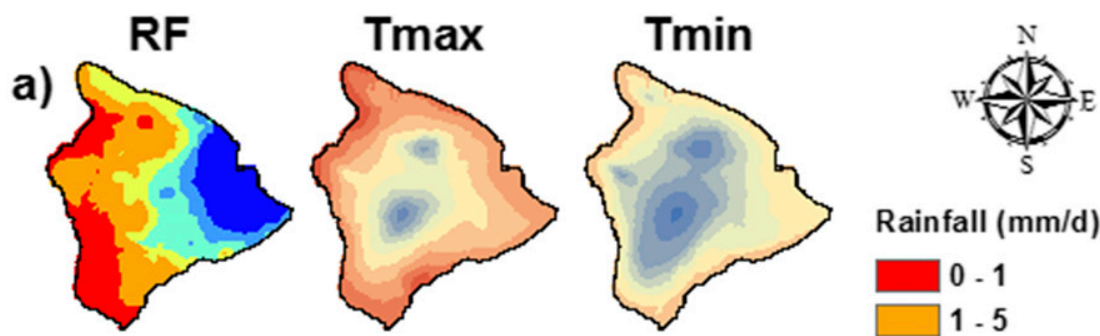

\section{Rainfall (mm/d)}

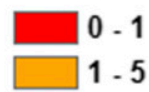

b)
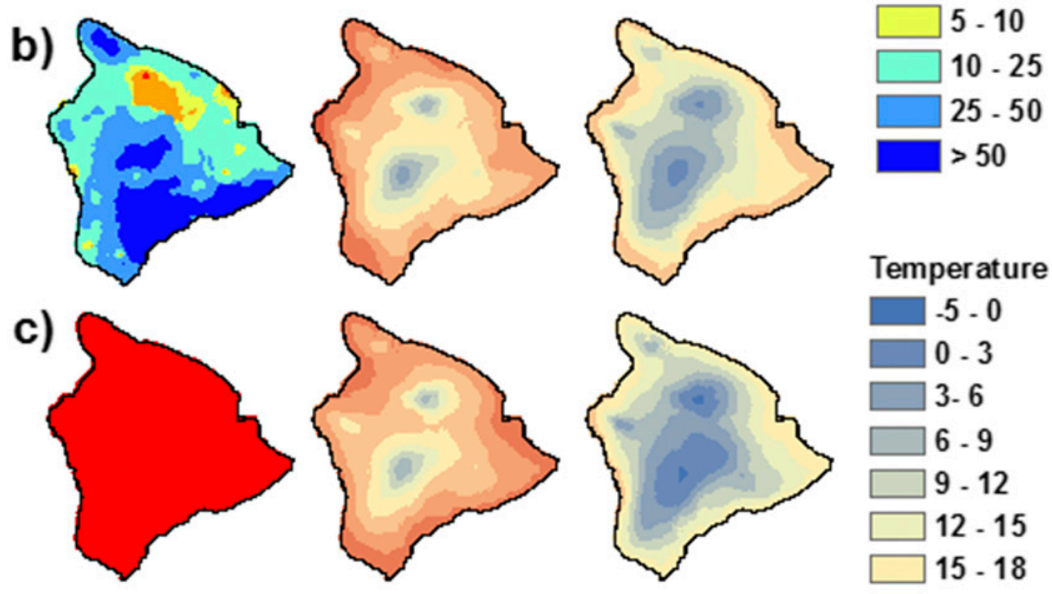

Temperature $\left({ }^{\circ} \mathrm{C}\right)$
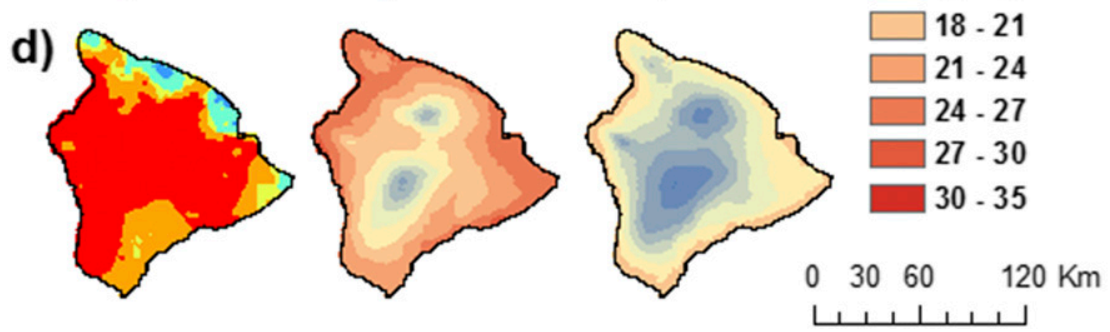

FIG. 6. Daily rainfall (RF), maximum temperature $T_{\max }$, and minimum temperature $T_{\min }$ for 1 Jan for (a) 1990, (b) 1993, (c) 1995, and (d) 2014 for Hawaii Island.

Camera et al. (2014) relative errors were calculated at each station for days when nonzero rainfall was observed (51\% of the dataset). Relative errors are calculated by dividing the MED and MAD statistics by the mean rainfall at a given station and then taking the average of these errors at all stations. Other error metrics used in the analysis to assess uncertainty are mean absolute error (MAE), mean bias error (MBE), and root-mean-square error (RMSE).
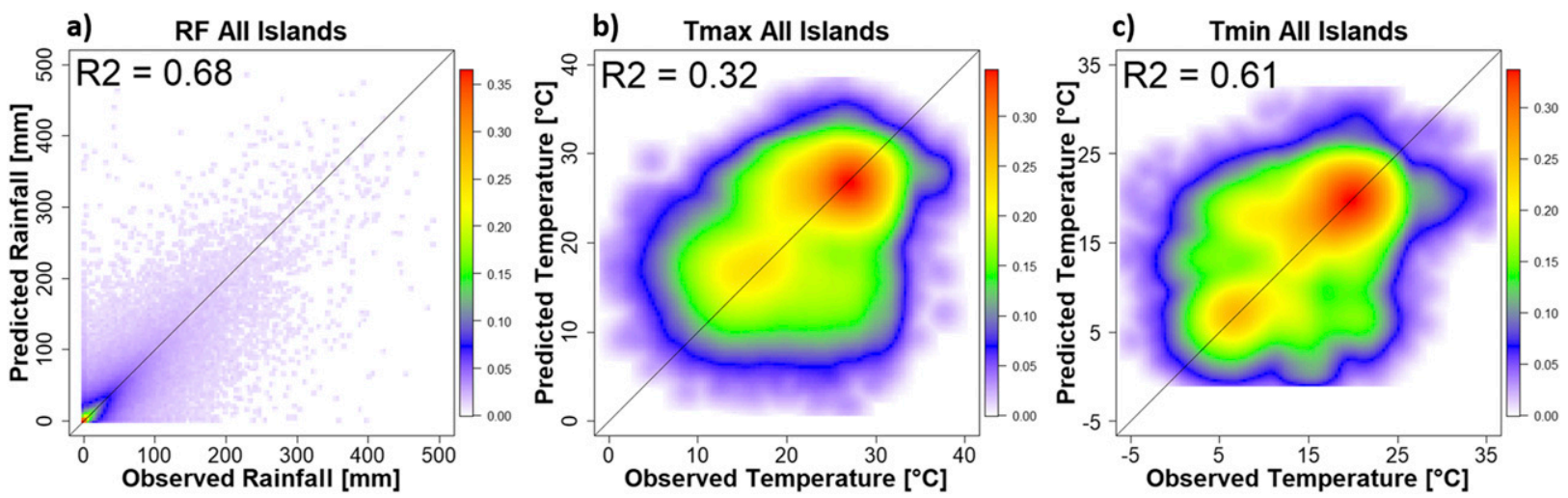

FIG. 7. All station observations compared with all cross-validation results for (a) rainfall, (b) $T_{\max }$, and (c) $T_{\min }$; heat maps show the density of points in relation to a 1:1 fit. 
A contingency table was created to assess the accuracy of rainfall event prediction. Here, the term "event" refers to predicted or observed rainfall at or above thresholds set at $0.1-\mathrm{mm}$ increments for rainfall $\leq 1 \mathrm{~mm}$ and at $1-\mathrm{mm}$ increments for rainfall $>1 \mathrm{~mm}$. Every cross-validation point was assigned to one of four discrete categories: hit $a$, where the predicted event occurs and observed rainfall is greater than or equal to the threshold; false alarm $b$, where the predicted event does not occur and observed rainfall is less than the threshold; miss $c$, where the event occurs when not predicted and rainfall is greater than or equal to the threshold when rainfall less than the threshold is predicted; and correct negative $d$, where the event is not predicted and does not occur and rainfall less than threshold is observed when rainfall less than threshold predicted. Several measures of interpolation accuracy can be derived from combinations of the categorical data. We calculated the probability of detection [POD $=a /(a+c)]$, the false alarm ratio $[\mathrm{FAR}=b /(a+b)]$, the critical success index $[\mathrm{CSI}=a /(a+b+c)]$, and bias $[B=(a+b) /(a+c)]$ (Wilks 2006). POD is bounded by 0 (worst case) and 1 (best case), FAR is bounded by 0 (best case) and 1 (worst case), and CSI is used to determine whether the state of precipitation has been accurately predicted and attains a value of 1 for a perfect interpolation and a value of 0 for a random interpolation. If $B>1$ (overforecast), the event was forecast more than it was observed (Wilks 2006).

The climatological mean probability of precipitation $(\mathrm{PoP})$ is evaluated using the entire time series of daily station observations and the cross validation estimates at the nearest corresponding grid points. The PoP at each station is calculated as the number of rainy days (days with greater than $0.15 \mathrm{~mm}$ of rainfall) divided by the total number of days for both the observed and predicted datasets. The difference between observed and predicted $\mathrm{PoP}$ is used as a measure of prediction bias.

To determine the effect of seasonality on interpolation errors, a one-way analysis of variance (ANOVA) is used for each variable to determine if the degree of error differs between months. Spearman's coefficient of rank correlation $r_{s}$ is used to investigate the relationship between the magnitude of error and station count. Both the ANOVA and Spearman statistics were calculated using the average monthly MAE and station count for each island.

\section{Results}

\section{a. Mean temperature mapping}

A calibration and consistency check of the mean monthly temperature was executed by comparing longterm monthly means of station data over the period of record with predicted map values. Mean errors were
TABLE 3. Descriptive statistics for LOOCV rainfall errors. RF ALL is all rainfall, $\mathrm{RF}<1$ is all rainfall less than $1 \mathrm{~mm}, \mathrm{RF}>1$ is all rainfall greater than $1 \mathrm{~mm}, \mathrm{MED}$ is the median error, MAD is the median deviation, sd is the standard deviation of errors, $r$ is the correlation coefficient, $n$ is the high number of point estimates used in the analysis, $\mathrm{n} 2$ is the number of point estimates where rainfall is $>0 \mathrm{~mm}$, and Hawaii is Hawaii Island.

\begin{tabular}{|c|c|c|c|c|c|}
\hline & & Hawaii & Maui Nui & Oahu & Kauai \\
\hline \multicolumn{6}{|c|}{ RF ALL } \\
\hline MED & $\mathrm{mm}$ & 0.5 & 0.0 & 0.6 & 0.5 \\
\hline MAD & $\mathrm{mm}$ & 0.5 & 0.0 & 0.5 & 0.5 \\
\hline MAE & $\mathrm{mm}$ & 2.6 & 1.5 & 2.3 & 2.6 \\
\hline sd & $\mathrm{mm}$ & 7.0 & 6.3 & 6.2 & 7.7 \\
\hline MBE & $\mathrm{mm}$ & 0.0 & 0.0 & 0.0 & -0.1 \\
\hline RMSE & $\mathrm{mm}$ & 7.5 & 6.5 & 6.6 & 8.1 \\
\hline$r$ & & 0.84 & 0.85 & 0.83 & 0.83 \\
\hline$n$ & & 754636 & 992502 & 773313 & 341700 \\
\hline MED & $\%$ & 51.5 & 45.4 & 55.3 & 49.5 \\
\hline MAD & $\%$ & 33.5 & 33.8 & 34 & 31.1 \\
\hline $\mathrm{n} 2$ & & 423639 & 359926 & 466604 & 215798 \\
\hline \multicolumn{6}{|c|}{$\mathrm{RF}<1$} \\
\hline MED & $\mathrm{mm}$ & 0.1 & 0.0 & 0.2 & 0.1 \\
\hline MAD & $\mathrm{mm}$ & 0.1 & 0.0 & 0.2 & 0.1 \\
\hline MAE & $\mathrm{mm}$ & 0.8 & 0.4 & 0.8 & 0.7 \\
\hline sd & $\mathrm{mm}$ & 3.3 & 2.3 & 2.5 & 2.6 \\
\hline MBE & $\mathrm{mm}$ & 0.8 & 0.3 & 0.7 & 0.6 \\
\hline RMSE & $\mathrm{mm}$ & 3.4 & 2.3 & 2.7 & 2.7 \\
\hline$r$ & & 0.11 & 0.11 & 0.11 & 0.13 \\
\hline$n$ & & 444451 & 742601 & 458857 & 194829 \\
\hline MED & $\%$ & 96.7 & 84.5 & 91.1 & 82.4 \\
\hline MAD & $\%$ & 66.8 & 46.5 & 58.2 & 55.1 \\
\hline $\mathrm{n} 2$ & & 113454 & 110025 & 152148 & 68927 \\
\hline \multicolumn{6}{|c|}{$\mathrm{RF}>1$} \\
\hline MED & $\mathrm{mm}$ & 2.3 & 1.8 & 2.0 & 1.8 \\
\hline MAD & $\mathrm{mm}$ & 1.7 & 1.4 & 1.4 & 1.4 \\
\hline MAE & $\mathrm{mm}$ & 5.2 & 4.8 & 4.6 & 5.1 \\
\hline sd & $\mathrm{mm}$ & 9.6 & 11.2 & 8.7 & 10.8 \\
\hline MBE & $\mathrm{mm}$ & -1.1 & -1.1 & -0.9 & -0.9 \\
\hline RMSE & $\mathrm{mm}$ & 10.9 & 12.2 & 9.8 & 12 \\
\hline$r$ & & 0.83 & 0.83 & 0.82 & 0.82 \\
\hline$n$ & & 312481 & 251623 & 316972 & 147761 \\
\hline MED & $\%$ & 41.7 & 38.2 & 44.8 & 40.7 \\
\hline MAD & $\%$ & 26.6 & 26.5 & 26.7 & 24.7 \\
\hline $\mathrm{n} 2$ & & 312481 & 251623 & 316972 & 147761 \\
\hline
\end{tabular}

identified for all of the 142 stations used in the mapping effort. In addition, spatial (by elevation) and temporal (by season) errors were also assessed. In general, mean monthly interpolation based on the segmented linear regression technique produced reasonable results with MAE of $\pm 1.5^{\circ} \mathrm{C}$ and $\pm 1.4^{\circ} \mathrm{C}$ for $T_{\max }$ and $T_{\min }$, respectively (Table 2). Maximum temperature was overpredicted $\left(+0.8^{\circ} \mathrm{C}\right)$ while predictions of $T_{\min }$ did not show bias in either direction. For $T_{\max }$, a seasonal pattern was evident with higher RMSE between June and September relative to the rest of the year (Fig. 2). In general, errors were similar between the high $(\geq 2100 \mathrm{~m})$ and low $(<2100 \mathrm{~m})$ 


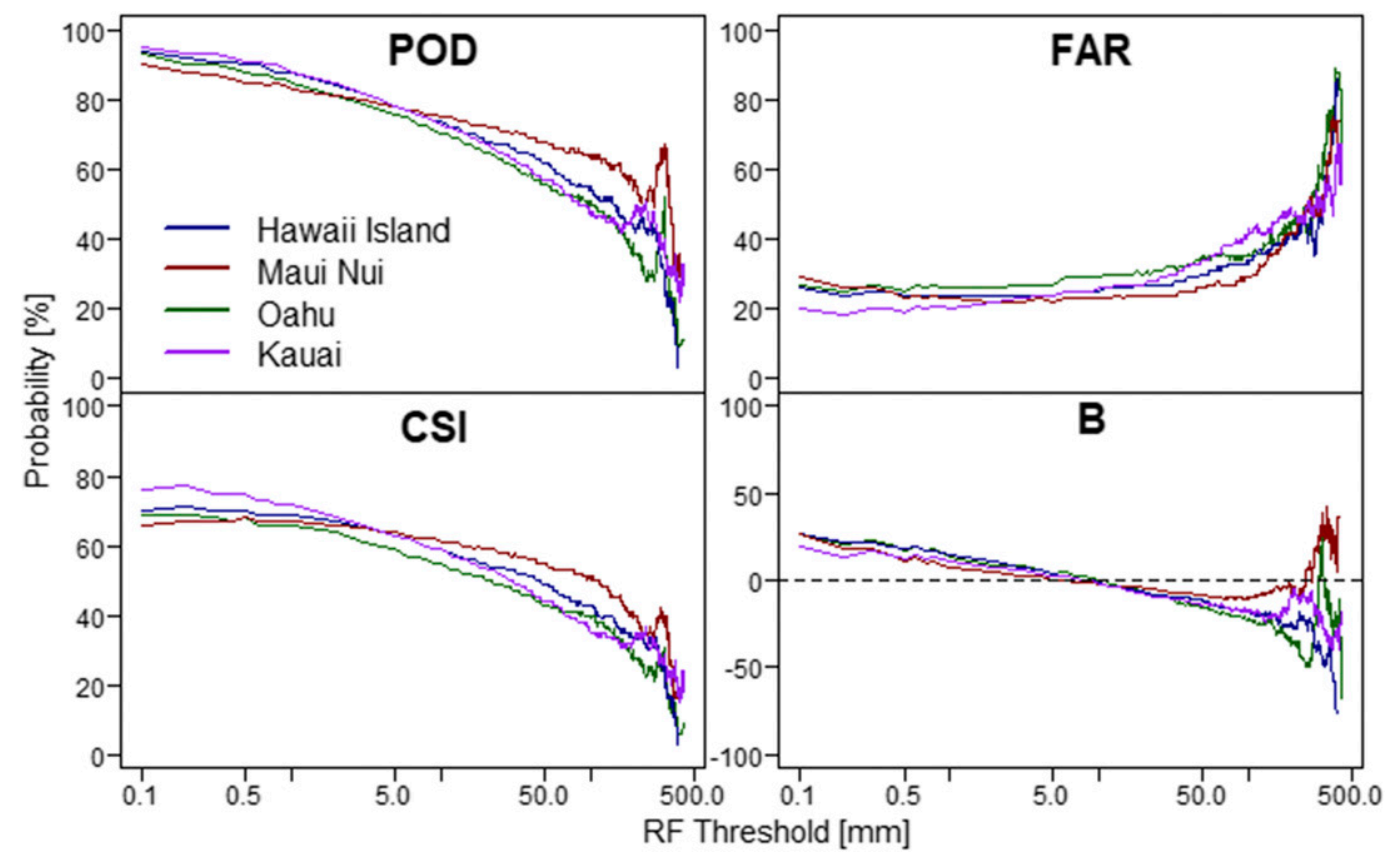

FIG. 8. Contingency statistics for rainfall events depicted as a function of the rainfall threshold level: (top left) POD, (top right) FAR, (bottom left) CSI, and (bottom right) $B$.

elevation stations for $T_{\max }$. For $T_{\min }$ errors were slightly lower at high elevation.

We compare the mean monthly $T_{\max }$ and $T_{\min }$ climatology maps (L_Maps) with the maps produced by G14 (Fig. 3). On average, G14_Maps for $T_{\max }$, had lower values than the $\mathrm{L} \_$Maps $\left(-3.6^{\circ} \pm 0.3^{\circ} \mathrm{C}\right)$ and the largest differences were found at high elevations on Maui and Hawaii Island. For $T_{\min }$, G14_Maps consistently gave higher values than the L_Maps, although the differences were much smaller $\left(+1.4^{\circ} \pm 0.4^{\circ} \mathrm{C}\right)$ than for $T_{\max }$. The pronounced differences in $T_{\max }$ between the two gridded products at high elevations might be explained by larger number of high-elevation stations used to derive the high-elevation regression equation. In general, we are more confident in the L_Maps because they make use of more input data to derive regression equations and specifically more data from representative highelevation stations.

\section{b. Mapping daily rainfall and temperature}

To illustrate the results of the rainfall interpolation, Fig. 4 shows maps of rainfall for 1 January of each year in the 25-yr period of record on Hawaii Island. The windward-leeward pattern is captured in the maps with the highest rainfall values typically occurring on the north- and east-facing shores and the lowest rainfall occurring on the south- and west-facing shores. Extreme interannual variability is captured within this time series as well, with almost no rainfall observed in
1995 and 2003 maps and island-wide rainfall observed in the 1993 and 2005 maps. In addition, several localized rainfall events were captured in the various maps.

For temperature, we show representative days for the wet season (1 January) and the dry season (1 July) variations for both $T_{\max }$ and $T_{\min }$ for six sample years (Fig. 5). Seasonal and interannual variations are apparent for both $T_{\max }$ and $T_{\min }$. To highlight how rainfall influences $T_{\max }$ and $T_{\min }$ at the daily time step we selected four days (1 January, different years) representing a range of rainfall patterns on Hawaii Island and examined the $T_{\max }$ and $T_{\min }$ patterns on those same days (Fig. 6). Differences are subtle, but the wettest day (Fig. 6b) had the lowest $T_{\min }$ and the driest day (Fig. 6c) had the highest $T_{\max }$ among the days used in the comparison, which is the pattern that would be expected.

We compare all of the cross-validation data results with observations for rainfall and temperature to determine the overall linear fit (Fig. 7). The majority of pairs are close to the 1-1 line for all three plots, however, some scatter exists. Of the three variables, rainfall predictions were most highly correlated with observations, followed by $T_{\min }$ and then $T_{\max }$.

\section{c. Island interpolation errors}

A summary of rainfall interpolation error metrics is given in Table 3. Relative MED errors (averaged from all stations) ranged from $45 \%$ to $55 \%(\mathrm{MED}=0-0.6 \mathrm{~mm})$ 
a)

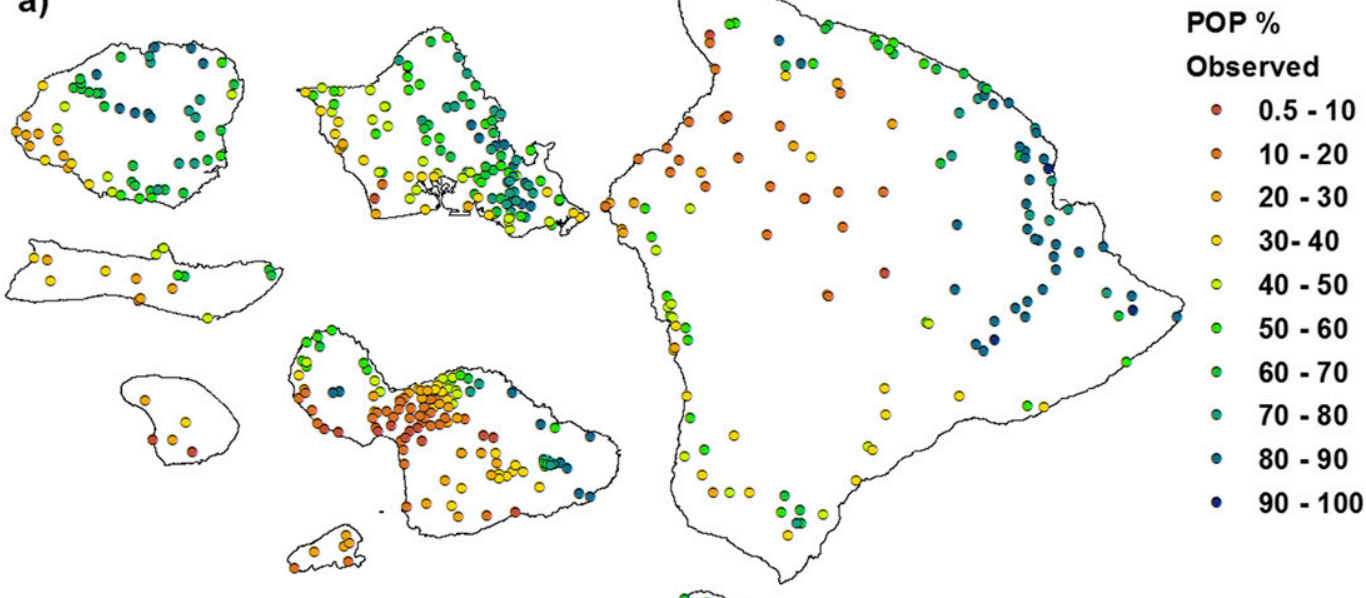

b)
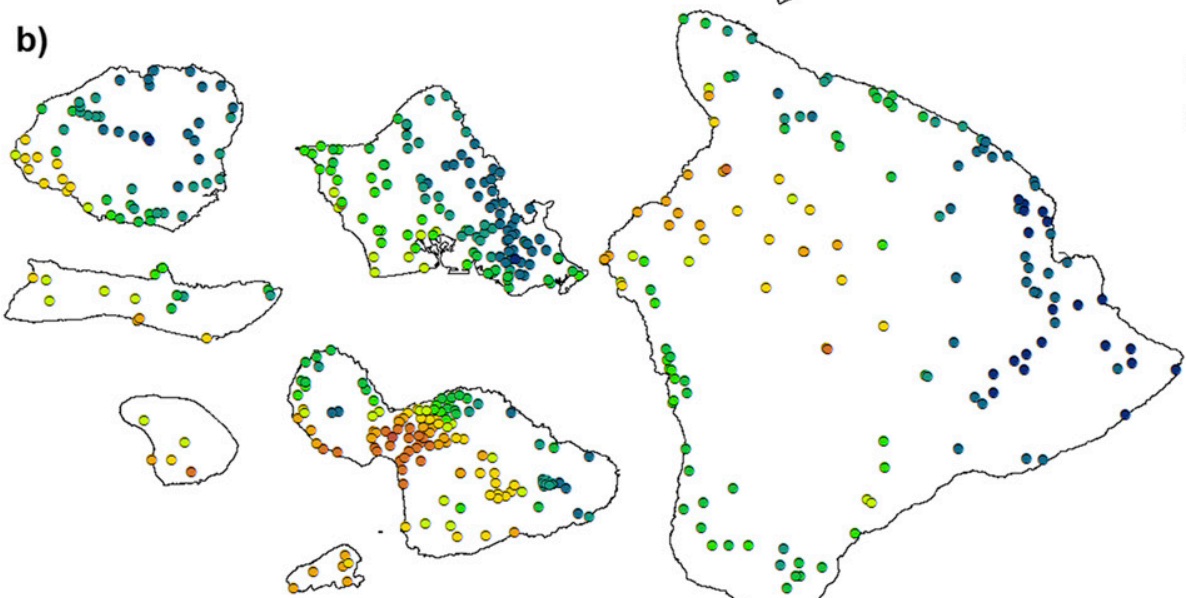

POP $\%$

Predicted
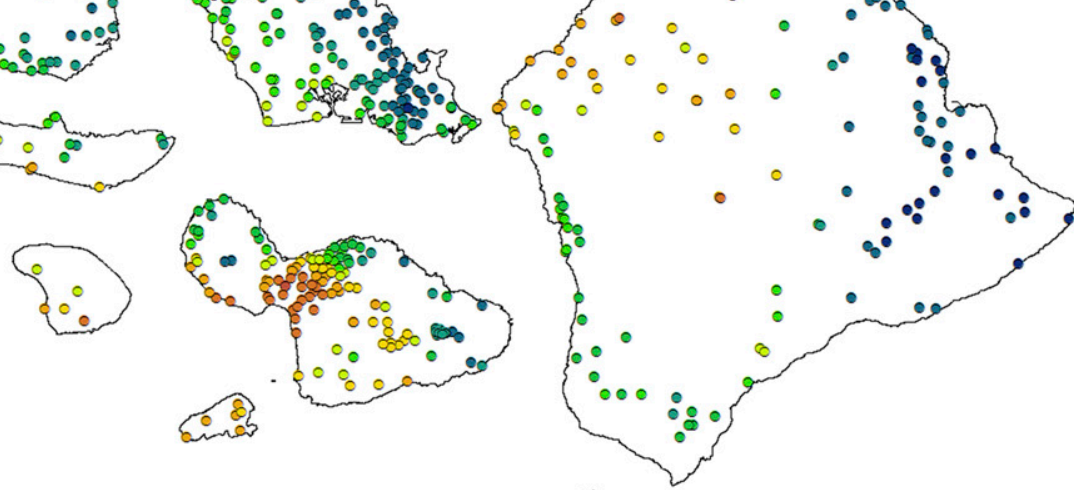

- $0.5-10$

- $10-20$

- $20-30$

- $30-40$

- $40-50$

- $50-60$

- $60-70$

- $70-80$

- $80-90$

- $90-100$

c)
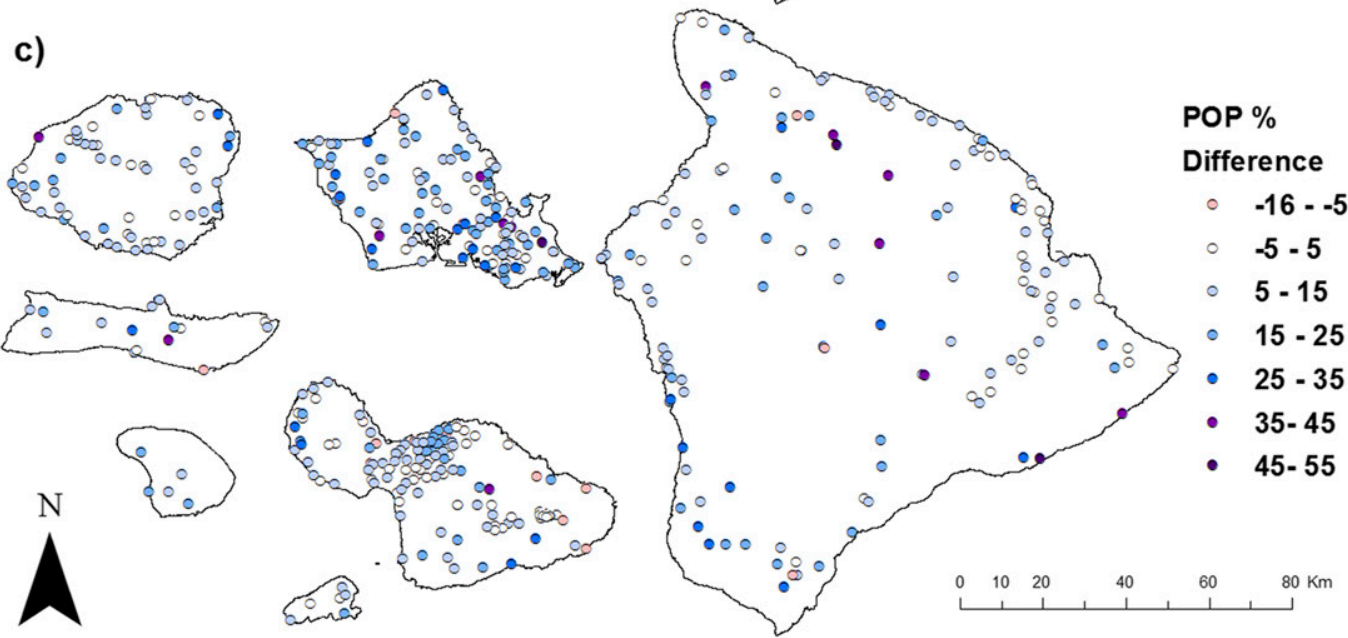

POP $\%$

Difference
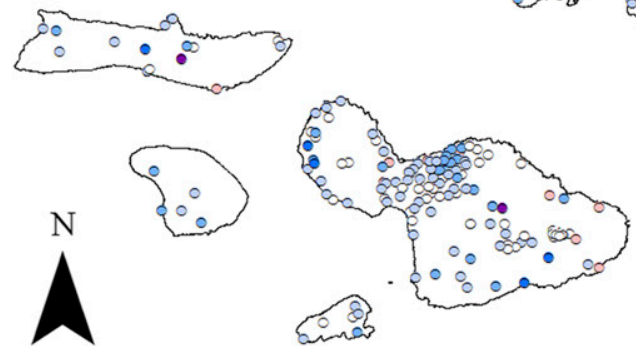

FIG. 9. PoP analysis for (a) rainfall observations at each station location, (b) rainfall predictions at grid cells corresponding to stations, and (c) the bias (predicted PoP - observed PoP) at each location. 
TABLE 4. Descriptive statistics for LOOCV maximum and minimum air temperature.

\begin{tabular}{lcccc}
\hline \hline & Hawaii & Maui Nui & Oahu & Kauai \\
\hline MED & 3.2 & $T_{\max }\left({ }^{\circ} \mathrm{C}\right)$ & & \\
MAD & 2.1 & 3.3 & 2.5 & 3.5 \\
MAE & 4.2 & 2.1 & 1.5 & 2 \\
sd & 3.5 & 4.3 & 2.9 & 4 \\
MBE & 0.6 & 3.7 & 2.2 & 2.9 \\
RMSE & 5.4 & 1.4 & 0.6 & 1.6 \\
$r$ & 0.17 & 5.6 & 3.7 & 5 \\
$n$ & 231964 & 300701 & 201573 & 36695 \\
& & & & \\
MED & 3.4 & 2.56 & \\
MAD & 2.4 & 1.5 & 2.4 & 3.2 \\
MAE & 4.7 & 3.2 & 3.5 & 1.9 \\
sd & 3.9 & 3.1 & 2.4 & 3.8 \\
MBE & 1.7 & 1.2 & 0.5 & 2.9 \\
RMSE & 6.1 & 4.5 & 3.8 & 4.6 \\
$r$ & 0.32 & 0.77 & 0.07 & 0.28 \\
$n$ & 272114 & 289775 & 170257 & 49050 \\
\hline
\end{tabular}

across the four islands. A strong and consistent relationship was found between the predicted and observed values with $r$ ranging from 0.83 to 0.85 across the four islands.

For rainfall $<1 \mathrm{~mm}$ ( $64 \%$ of the data), a tendency to overpredict the observed rainfall $(\mathrm{MBE}=+0.6 \mathrm{~mm})$ was identified. Correlation between the predicted and observed data in this category was not strong on any of the islands $(r=0.11-0.13)$, which suggests that day-to-day variability within this low rainfall range is not well represented by the interpolation scheme. When only nonzero values were examined ( $24 \%$ of the rainfall data $<1 \mathrm{~mm})$ the relative MED error ranged from $82 \%$ to $97 \%$ across the four islands. This large error was not surprising considered the fact that even a small overprediction of low rainfall can translate into large relative errors.

For rainfall $\geq 1 \mathrm{~mm}$ ( $36 \%$ of the data), the relative error was lower $(38 \%-45 \%)$ than for rainfall $<1 \mathrm{~mm}$ and a mean tendency for an underprediction of rainfall $(\mathrm{MBE}=-1.1 \mathrm{~mm})$ was identified. Negative bias is not introduced until rainfall exceeds the $\sim 10 \mathrm{~mm}$ as can be seen in Fig. 8. The median absolute error across the islands was only $2 \mathrm{~mm}$. In general, the correlation was much stronger between the predicted and observed values ( $r=0.82-0.83$ ) for this subset of the data.

The contingency table metrics, POD, FAR, CSI, and $B$, derived from rainfall estimates, are shown in Fig. 6. POD and CSI were highest for the lowest rainfall thresholds and decreased as the rainfall thresholds increased. For all of the islands, a positive bias was identified when rainfall was below the $\sim 10 \mathrm{~mm}$ threshold and negative bias was identified when rainfall exceeded this threshold. At the highest thresholds $(<250 \mathrm{~mm})$, consistent overpredictions were found on Maui Nui. This is most likely the result of observation stations located in the wettest areas on the east side of the island of Maui interpolating additional, false rainfall to areas that are in reality much drier.

Results from the PoP analysis indicate that rainfall prediction varies considerably by station (Fig. 9). PoP is highest along windward slopes at elevations just below the mean TWI. In these areas, rainfall occurs between $70 \%$ and $94 \%$ of the time (PoP). At lower elevations and on leeward exposures the PoP can be less than $10 \%$. In general, the predicted results agree with observed patterns, however, the mean bias error was $+11.5 \%$ (range: from -16 to $+55 \%$ ). Some of the highest bias was found at high-elevation stations on Hawaii Island and Maui Nui at elevations near or above the mean TWI. This is not surprising considering on any given day the TWI could be above or below these points, thus producing extremely dry or wet conditions that were not well predicted by the conditions at neighboring stations used in the interpolation.

The descriptive statistics for the LOOCV of $T_{\max }$ and $T_{\min }$ are presented in Table 4 . On average, predicted values were greater than observations for both $T_{\max }$ $\left(\mathrm{MBE}=+1.0^{\circ} \mathrm{C}\right)$ and $T_{\min }\left(\mathrm{MBE}=+1.5^{\circ} \mathrm{C}\right)$ across the island chain. MED absolute errors ranged from $\pm 2.5^{\circ}$ to $\pm 3.5^{\circ} \mathrm{C}$ for $T_{\text {max }}$ and from $\pm 2.4^{\circ}$ to $\pm 3.4^{\circ} \mathrm{C}$ for $T_{\text {min }}$ across all islands. Correlations $r$ between predicted and observed data were weak on all islands $(r=0.10-0.17)$ except for Maui Nui $(r=0.56)$, which is most likely explained by the fact that Maui Nui consists of four individual islands.

\section{d. Station interpolation error}

Global statistics are useful for characterizing islandwide errors but do not provide information on how the interpolation performance varied across the gridded surface. In Fig. 10, we show both the MED and the relative MED error at each of the 471 stations used in the rainfall interpolation. In general, the driest (leeward high elevation) and the most remote stations have the lowest MED errors and the highest relative MED errors. The wettest (windward low elevation) stations had the highest MED errors and the lowest relative MED errors. Stations located in areas with high station density typically have lower errors than stations in remote areas. No relationship between elevation and error was identified. Therefore, when interpreting the error at an individual station it is important to consider not only the map error at an individual station but the rainfall characteristics at that station as well. When relative errors are calculated by day (not by station) we find the same relationship between wet/dry days as we do wet/dry stations. The driest days have the highest relative errors and wettest days have the lowest relative errors. Essentially, the spatial variation in rainfall on any given 


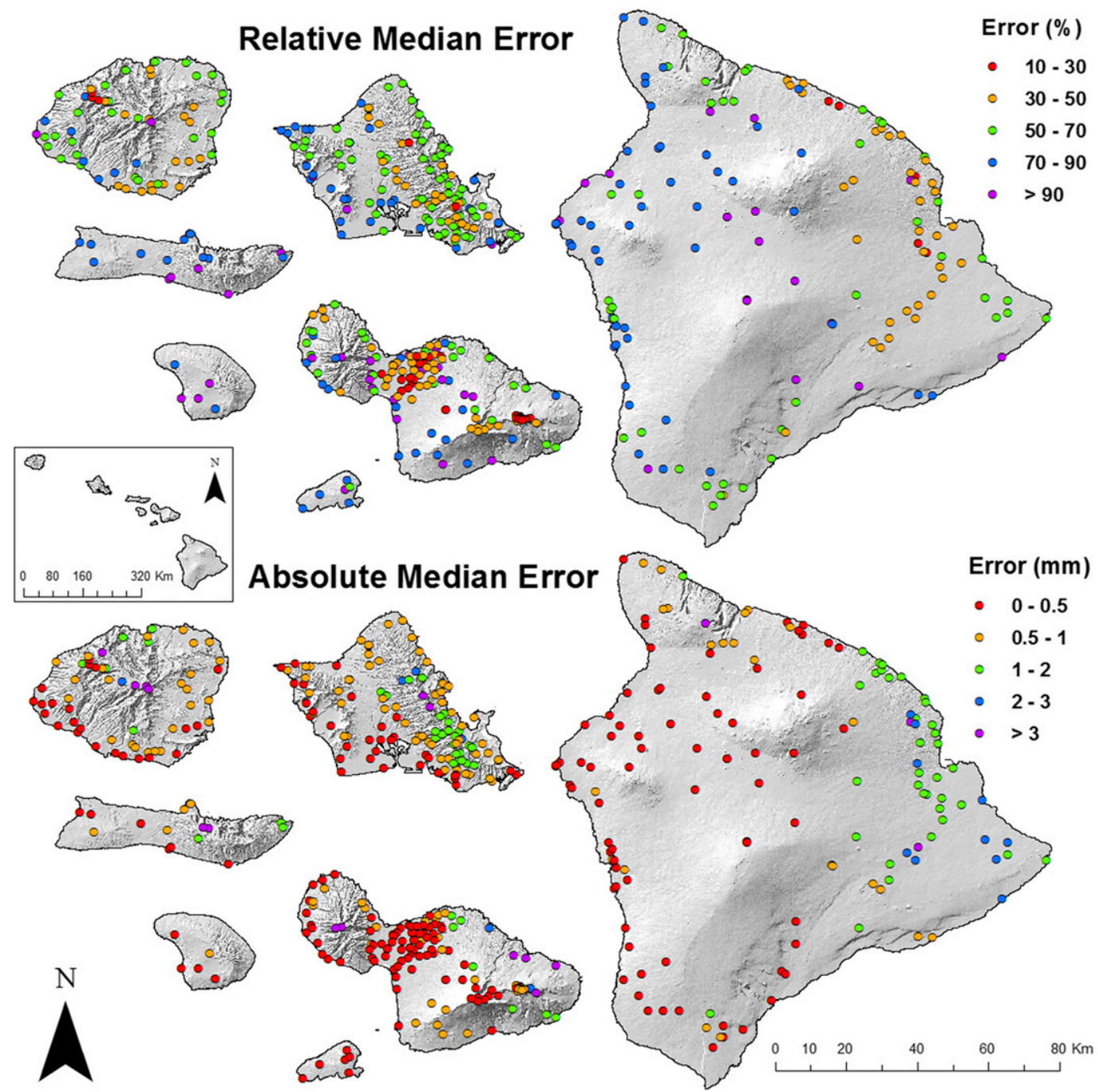

FIG. 10. Spatial distribution of (top) relative median errors and (bottom) absolute median absolute errors in rainfall prediction across the state of Hawaii.

day will influence the error at a particular station. Rainfall events that are more localized, will produce higher overall errors than events that are more widespread (Camera et al. 2014).

To highlight the influence of specific stations on the interpolated surfaces, we plot the station observations directly over the predicted surfaces for 1 January of four different years for the island of Hawaii (Fig. 11). On the wettest of the four days shown (Fig. 11b), MAE was $14.6 \mathrm{~mm}$, on the driest day of the four (Fig. 11c) MAE was $<0.01$.

The MAE at each of the 142 stations used in the temperature interpolation for $T_{\max }$ and $T_{\min }$ are shown in Fig. 12. The highest errors were found at high elevations on the Hawaii Island for both $T_{\max }$ and $T_{\min }$. Errors were low at high elevations on Haleakala volcano, where station density is high. Again, no relationship between elevation and error was identified.

\section{e. Seasonal interpolation errors}

LOOCV results were analyzed to identify the effects of season and the number of available predictor stations on the associated errors. ANOVA identified a significant $(\alpha=0.05)$ difference in MAE between seasons for all variables and on all of the islands (Table 5). Wet season months (November-April) had significantly ( $p<$ $0.05)$ higher errors than during the dry season months (May-October) for rainfall (Fig. 13). The difference in errors between calendar months on each of the four Islands ranged from 1.2 to $1.6 \mathrm{~mm}$ and the total range of errors on all of the islands was $0.8 \mathrm{~mm}$ (June, Maui Nui) to $3.5 \mathrm{~mm}$ (February, Kauai). For $T_{\max }$ and $T_{\min }$ results 


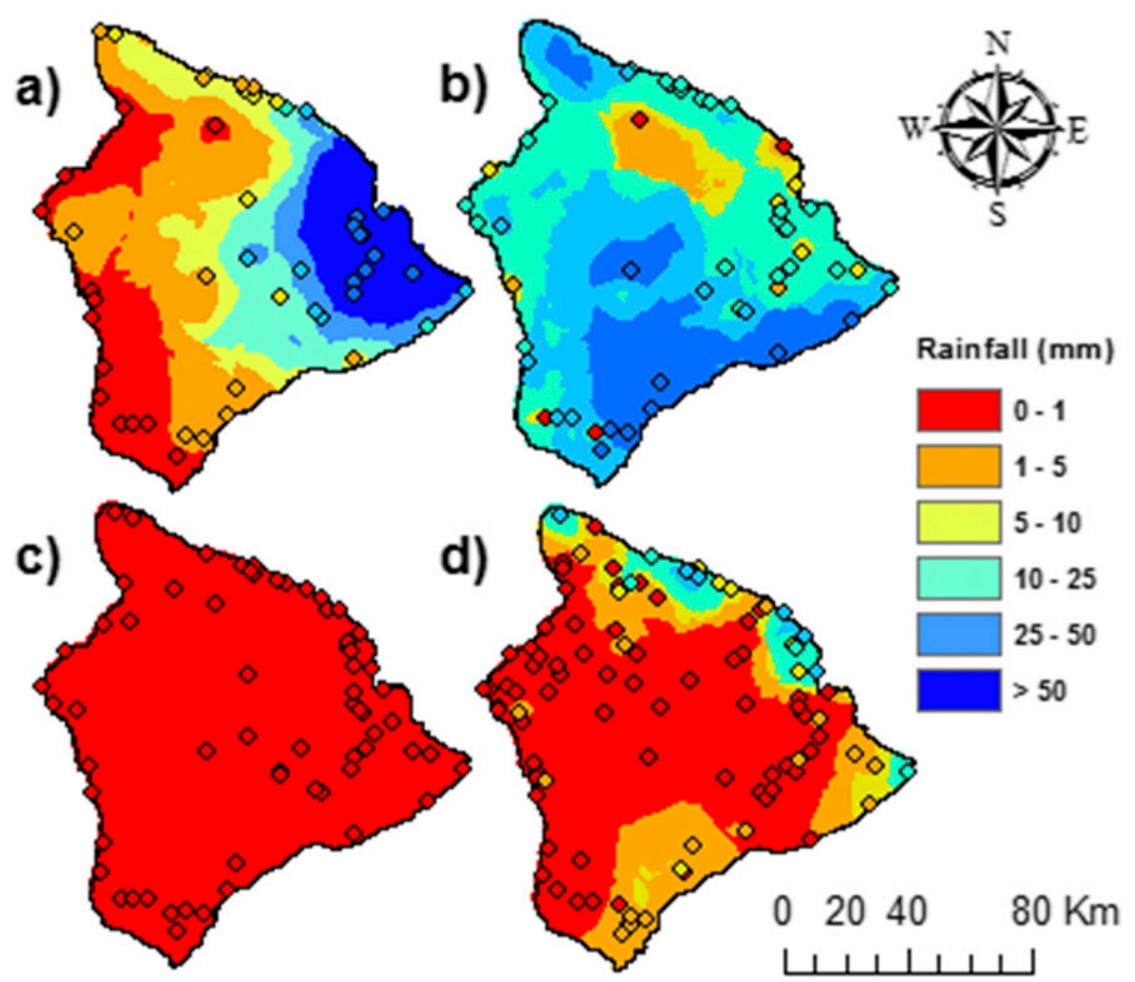

FIG. 11. Interpolated rainfall and station rainfall observations for 1 Jan of four different years: (a) 1990, (b) 1993, (c) 1995, and (d) 2014. Both interpolated stations and observations are set to the same color scale. Years were selected to show a range of different rainfall patterns.

varied by island and the highest average errors were found during the coldest months (January-March) except on Maui, where the highest errors were found between May and September. Overall, the range in monthly average errors over the year for both $T_{\max }\left(0.6^{\circ}-1.2^{\circ} \mathrm{C}\right)$ and $T_{\min }\left(0.9^{\circ}-1.8^{\circ} \mathrm{C}\right)$ was small.

The Spearman's rank correlation coefficient was used to determine if the number of stations used in the daily interpolation had an effect on the error. For rainfall, results indicate a weak to moderate negative relationship between MAE and the number of available stations (Table 6). This relationship was found to be significant only on the island of Oahu $(p=0.04)$. For $T_{\max }$, the relationship between station count and error was negative for Hawaii, Maui Nui, and Kauai but positive for Oahu (all relationships were significant). For $T_{\min }$, the strongest dependence on station number was found on Hawaii Island and a significant relationship was identified between the two variables on Hawaii Island, Maui Nui, and Kauai.

\section{Summary and discussion}

In this work, 250-m gridded datasets for daily rainfall and near-surface air temperature (minimum and maximum) for the period 1990-2014 were created for the main Hawaiian Islands. The datasets were produced using a climatologically aided interpolation (CAI) scheme, where the station anomalies were interpolated using an optimized inverse distance weighting approach, and then combined with mean maps to produce daily maps for each of the three variables. The maps are spatially and serially complete throughout the 25-yr period (three sets of 9131 grids with no gaps).

In this analysis, the MAE for gridded rainfall estimates is $2.3 \mathrm{~mm}$ when all rainfall was considered. These errors were similar to MAE for daily predictions of precipitation reported by Hunter and Meentemeyer (2005) for California, who used a similar CAI scheme to calculate anomalies and an ordinary kriging approach for predictions of daily rainfall and temperature at a coarser spatial resolution $(2 \mathrm{~km})$ across the state of California $(\mathrm{MAE}=2.5 \mathrm{~mm}$ ). Mean error statistics, however, may not be the most effective way to assess the overall quality of these maps. Errors in this study varied considerably across rainfall thresholds. When rainfall was low (rainfall $<1 \mathrm{~mm}$ ), relative errors were high, average probability of detection was high $(91 \%)$, and the average event prediction bias was $+20 \%$. When rainfall was greater than $1 \mathrm{~mm}$ and less than $10 \mathrm{~mm}$ the average probability of detection was $74 \%$ and the event 


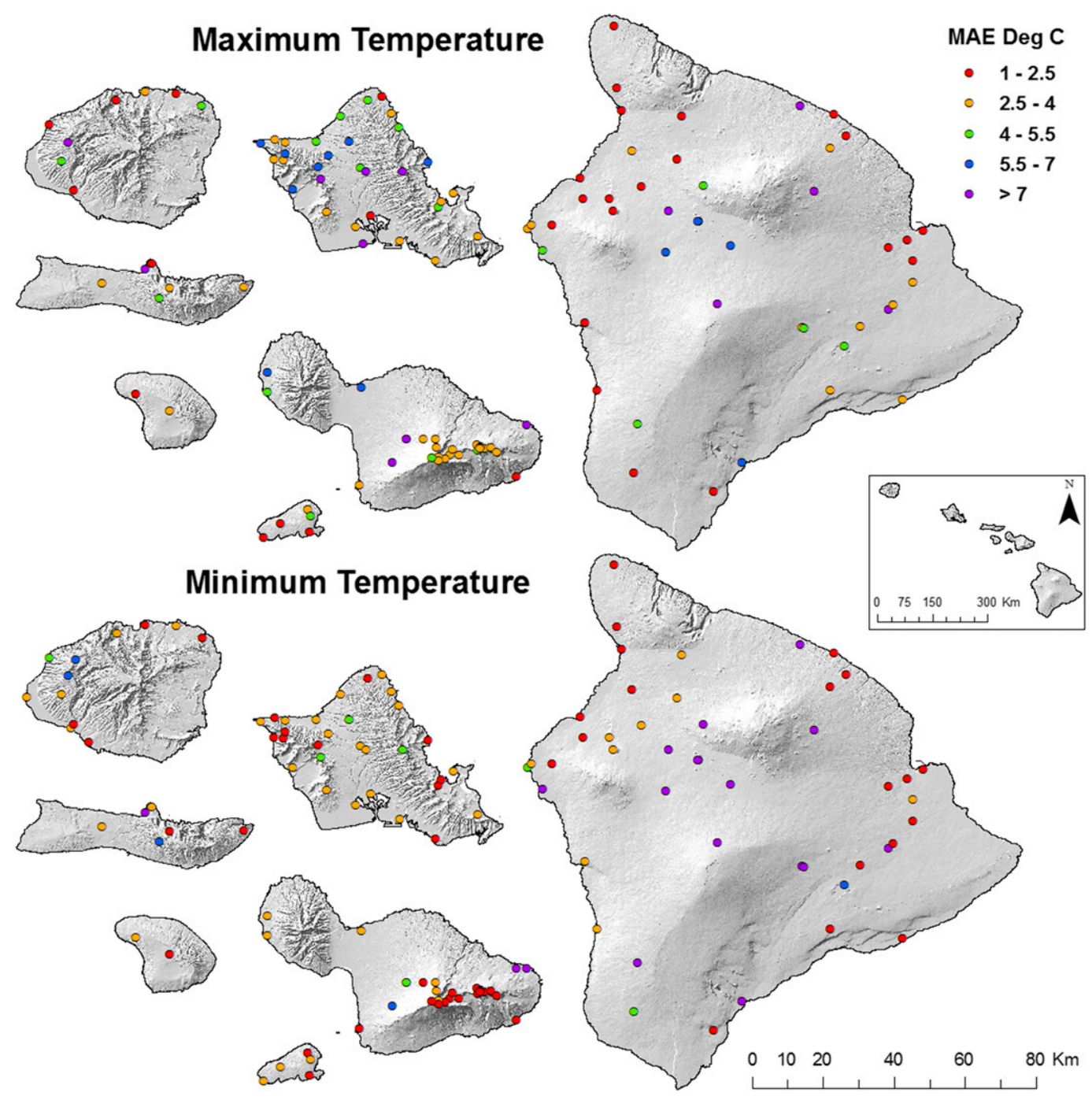

FIG. 12. Spatial distribution of MAE for (top) daily maximum and (bottom) daily minimum near-surface air temperature prediction across the state of Hawaii.

prediction bias was near zero. Beyond the $10-\mathrm{mm}$ threshold, detectability of rainfall events was lowered and event prediction bias became increasingly negative as rainfall increased. This pattern is primarily a result of an interpolation-related smoothing effect.

In complex topographical settings a sparse station network can introduce additional errors into the final data product. The idea behind IDW is that the stations closest to the interpolation point will have the greatest influence on that point. So, if station density is high in an area with homogeneous climatic conditions then uncertainty will be reduced. In areas of low station densities, uncertainty is increased especially if the interpolated point is drawing information from stations located in heterogeneous climatic zones (e.g., above versus below the TWI), subject to different wind exposure (e.g., windward versus leeward), or influenced by other, smaller-scale topographical discontinuities (e.g., ridge versus valley). This can be seen explicitly in the PoP analysis, where stations at or near the mean TWI have some of the highest bias. This is certainly one of the limitations of IDW, and this type of error is essentially unavoidable using this method.

TABLE 5. ANOVA test results. RF is rainfall, $F$ is the critical $F$ statistic, and $p$ is a measure of statistical significance.

\begin{tabular}{|c|c|c|c|c|c|c|c|c|}
\hline \multirow[b]{2}{*}{ Variable } & \multicolumn{2}{|c|}{ Hawaii } & \multicolumn{2}{|c|}{ Maui Nui } & \multicolumn{2}{|c|}{ Oahu } & \multicolumn{2}{|c|}{ Kauai } \\
\hline & $F$ & $p$ & $F$ & $p$ & $F$ & $p$ & $F$ & $p$ \\
\hline $\mathrm{RF}$ & 2.67 & 0.002 & 10.31 & 0.000 & 5.04 & 0.000 & 3.48 & 0.000 \\
\hline$T_{\max }$ & 7.87 & 0.000 & 4.65 & 0.000 & 2.68 & 0.002 & 2.49 & 0.005 \\
\hline$T_{\min }$ & 4.04 & 0.000 & 4.11 & 0.000 & 4.37 & 0.000 & 2.23 & 0.013 \\
\hline
\end{tabular}




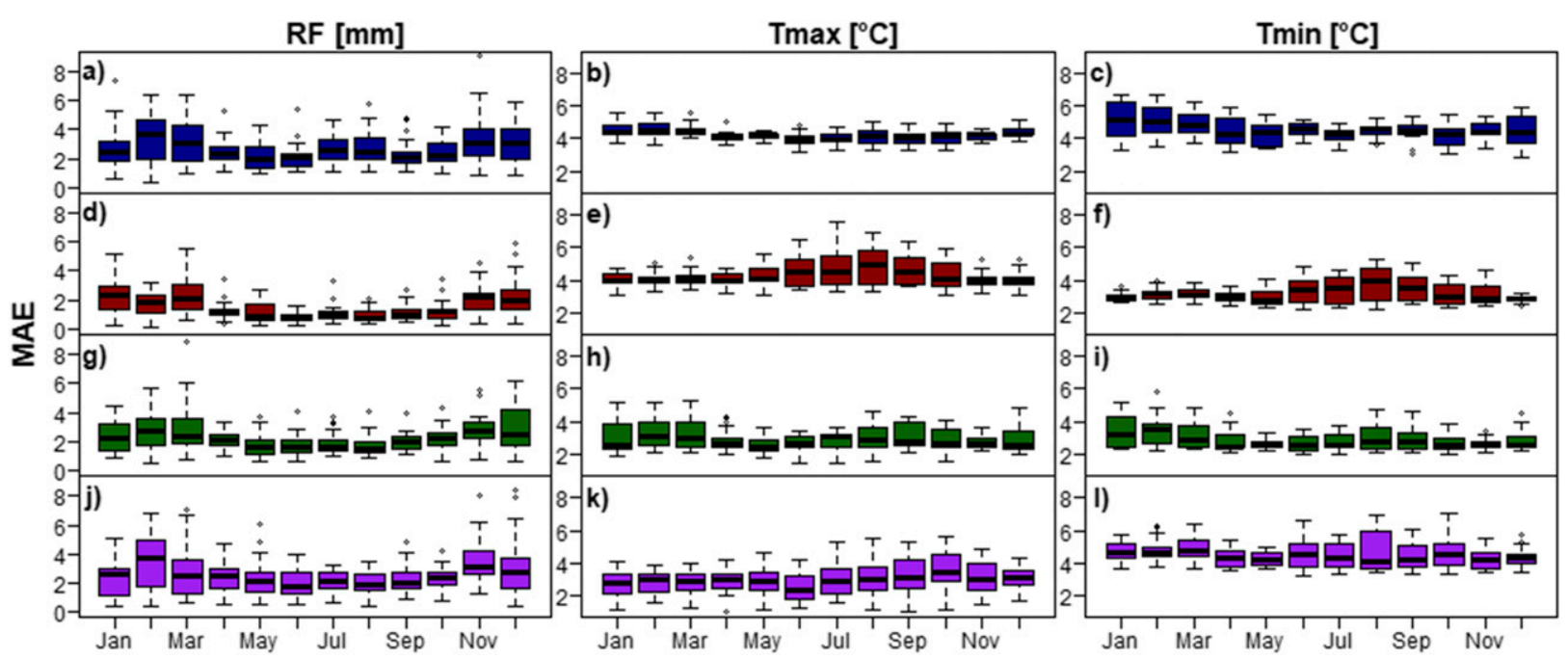

FIG. 13. Mean absolute monthly error of (left) rainfall, (center) maximum temperature, and (right) minimum temperature for (a)-(c) Hawaii Island, (d)-(f) Maui Nui, (g)-(i) Oahu, and (j)-(1) Kauai.

For temperature, the average prediction error was $\pm 3.8^{\circ}$ and $\pm 3.7^{\circ} \mathrm{C}$ for maximum and minimum temperature, respectively. A tendency for the interpolation method to overpredict temperature for $T_{\max }\left(\mathrm{MBE}=+1.1^{\circ} \mathrm{C}\right)$ and $T_{\min }\left(\mathrm{MBE}=+1.5^{\circ} \mathrm{C}\right)$ was identified. These errors are greater than the MAE for daily predictions of $T_{\max }$ $\left( \pm 2.0^{\circ} \mathrm{C}\right)$ and $T_{\min }\left( \pm 1.7^{\circ} \mathrm{C}\right)$ reported by Hunter and Meentemeyer (2005), who used ordinary kriging to interpolate data at a $2-\mathrm{km}$ spatial resolution. Errors shown here were also greater than errors presented by Dodson and Marks (1997), who used an IDW approach to interpolate temperature at a $1-\mathrm{km}$ resolution and reported MAE of $\pm 1.2^{\circ}$ and $\pm 1.3^{\circ} \mathrm{C}$ for $T_{\max }$ and $T_{\min }$, respectively. We consider the errors presented here to be quite large when compared to the diurnal range in temperature, however, as a first attempt at mapping daily temperature we are satisfied with the result. All interpolated estimates have errors. We have characterized these errors through cross-validation to allow data users to assess the level of uncertainty in the gridded products.

The interpolation performance varied seasonally. For rainfall, this result may reflect differences among months in the amounts of rainfall received. This is likely a direct influence of the CAI approach due to the fact that rainfall can deviate more substantially from the climatological pattern in wet season months than dry season months. The lowest (highest) errors were found during the driest (wettest) months, but overall the range in errors was small $(<1.6 \mathrm{~mm})$. Interpolation errors for $T_{\max }$ and $T_{\min }$ also significantly differed between months and the range of these differences was also small $\left(<1^{\circ} \mathrm{C}\right)$ for Hawaii Island, Maui Nui, and Oahu. A slightly higher range in errors $\left(<1.8^{\circ} \mathrm{C}\right)$ on Kauai might be attributed to a small number of stations available for the LOOCV over the period of record.

We expected that interpolation error would increase as the number of available predictor stations decreased. For rainfall, correlations between error and the number of predictor stations were in the negative on Hawaii Island, Maui Nui, and Oahu (no relationship on Kauai), indicating that a decrease in station density can increase interpolation errors. For the temperature variables, mixed results were found in this same comparison. For $T_{\min }$, a decrease in station count increased errors on Maui Nui and decreased the errors on Hawaii Island, Oahu, and Kauai. One explanation for this discrepancy

TABLE 6. Spearman rank test results for the dependence of the error on station count, where $r_{s}$ is the Spearman's rank correlation coefficient.

\begin{tabular}{|c|c|c|c|}
\hline & $r_{s}$ & $p$ & Strength \\
\hline \multicolumn{4}{|c|}{ RF } \\
\hline Hawaii & -0.20 & 0.08 & Weak \\
\hline Maui Nui & -0.28 & 0.06 & Weak \\
\hline Oahu & -0.41 & 0.04 & Moderate \\
\hline Kauai & 0.00 & 0.24 & Very weak \\
\hline \multicolumn{4}{|c|}{$T_{\max }$} \\
\hline Hawaii & -0.16 & 0.01 & Weak \\
\hline Maui Nui & -0.49 & 0.00 & Moderate \\
\hline Oahu & 0.23 & 0.00 & Weak \\
\hline Kauai & 0.14 & 0.00 & Very weak \\
\hline \multicolumn{4}{|c|}{$T_{\min }$} \\
\hline Hawaii & 0.72 & 0.00 & Strong \\
\hline Maui Nui & -0.36 & 0.00 & Weak \\
\hline Oahu & 0.02 & 0.75 & Very weak \\
\hline Kauai & 0.29 & 0.00 & Weak \\
\hline
\end{tabular}


is that regression equations used to create the mean $T_{\max }$ and $T_{\min }$ maps were derived from data originating from all of the islands, thus biasing results for individual islands. For example, the correlations on Maui Nui between station density and error were in the negative direction which is what would be expected. Maui Nui was also the island with the highest average number of stations for $T_{\max }$ and second highest for $T_{\min }$, as well as the island with the most number of stations above the mean TWI base height.

The CAI approach produces some level of consistency in day-to-day results regardless of the variation in the number of stations used in the interpolation because, at the very least, it captures the general pattern of mean temperature fields. Errors in both rainfall and temperature maps are introduced at the point of measurement, during the calculation of anomalies, and during the interpolation. For rainfall, it is important to consider that the magnitude of errors at individual stations, on individual days, and during different months/seasons are a function of the amount of rainfall received. In terms of relative error, this method presented here consistently performs better with increasing rainfall. In general, the drier the station/day/month/season the higher the error will be. Camera et al. (2014) identified a similar pattern with IDW interpolation at the daily time step suggesting that the spatial variation in rainfall on any given day will influence the error at a particular station. The crossvalidation results of this study clearly show how the amount of rainfall at a given station, the different spatial variability of stations, and the different densities in the original observation dataset can influence uncertainty. We encourage all users of these products to avail themselves of the detailed uncertainty analysis provided here when analyzing environmental phenomena based on these products.

The methods presented here provide an effective distance-weighted approach for mapping rainfall and temperature in a topographically diverse region and at a fine temporal resolution. The integration of longterm climate maps with point observations, helps to improve the accuracy of the daily maps, because geographical features such as varied terrain, proximity to the coast, exposure to the prevailing winds, and the influence of the TWI are retained in each map. Compared with other mapping efforts at the daily time step (using various methods and at various spatial scales), MAE errors presented here were similar for rainfall but higher for both $T_{\max }$ and $T_{\min }$ (see Dodson and Marks 1997; Hunter and Meentemeyer 2005; Hofstra et al. 2008). Despite known errors, this approach provides a valuable dataset for a wide range of geographical research requiring spatially explicit maps of these variables.
Ongoing research efforts will continue to examine tunable portions of the CAI approach, including possible addition of explicit prediction of occurrence of rainfall at each grid point (e.g., Thornton et al. 2012; Clark and Slater 2006; Newman et al. 2019a,b). Finally, we are currently developing infrastructure to produce near-real-time monthly (and eventually daily) maps of rainfall in Hawaii using these or other related methods.

Acknowledgments. The US Army Corps of Engineers (USACE) Climate Preparedness and Resilience program funded this work under an agreement with the National Center for Atmospheric Research (NCAR). We thank, Mike Nullet (University of Hawai'i at Mānoa, Geography Department), Nancy Matsumoto and Barry Usagawa (Honolulu Board of water supply), Gwen Jacobs and Ron Merrill (University of Hawai'i Information and Technology Services). The technical support and advanced computing resources from the University of Hawaii Information Technology Services-Cyberinfrastructure are gratefully acknowledged. A. Frazier was supported with funding from the National Bioclimatology and Climate Change Program, Washington Office, USDA Forest Service and from the Department of Interior Pacific Islands Climate Adaptation Science Center. The National Center for Atmospheric Research is sponsored by the National Science Foundation. Daily rainfall maps are available at https://doi.org/10.5065/D6X065VV, and daily $T_{\max }$ and $T_{\min }$ maps are available at https://doi.org/ 10.5065/D6SB44JV.

\section{REFERENCES}

Berezowski, T., M. Szczeniak, I. Kardel, R. Michalowski, T. Okruszko, A. Mezghani, and M. Piniewski, 2016: CPLFDGDPT5: High-resolution gridded daily precipitation and temperature data set for two largest Polish river basins. Earth Syst. Sci. Data, 8, 127-139, https://doi.org/10.5194/essd-8-127-2016.

Brinckmann, S., S. Krähenmann, and P. Bissolli, 2016: High-resolution daily gridded data sets of air temperature and wind speed for Europe. Earth Syst. Sci. Data, 8, 491-516, https://doi.org/10.5194/ essd-8-491-2016.

Buytaert, W., R. Celleri, P. Willems, B. De Bièvre, and G. Wyseure, 2006: Spatial and temporal rainfall variability in mountainous areas: A case study from the south Ecuadorian Andes. J. Hydrol., 329, 413-421, https://doi.org/10.1016/j.jhydrol.2006.02.031.

Camera, C., A. Bruggeman, P. Hadjinicolaou, S. Pashiardis, and M. A. Lange, 2014: Evaluation of interpolation techniques for the creation of gridded daily precipitation $\left(1 \times 1 \mathrm{~km}^{2}\right)$; Cyprus, 1980-2010. J. Geophys. Res. Atmos., 119, 693-712, https://doi.org/10.1002/2013JD020611.

Chen, M., P. Xie, J. E. Janowiak, and P. A. Arkin, 2002: Global land precipitation: A 50-yr monthly analysis based on gauge observations. J. Hydrometeor., 3, 249-266, https://doi.org/ 10.1175/1525-7541(2002)003<0249:GLPAYM>2.0.CO;2.

Clark, M. P., and A. G. Slater, 2006: Probabilistic quantitative precipitation estimation in complex terrain. J. Hydrometeor., 7, 3-22, https://doi.org/10.1175/JHM474.1. 
Croke, B. F. W., A. Islam, J. Ghosh, and M. A. Khan, 2011: Evaluation of approaches for estimation of rainfall and the unit hydrograph. Hydrol. Res., 42, 372-385, https://doi.org/ 10.2166/nh.2011.017.

Daly, C., R. P. Neilson, and D. L. Phillips, 1994: A statisticaltopographic model for mapping climatological precipitation over mountainous terrain. J. Appl. Meteor., 33, 140-158, https:// doi.org/10.1175/1520-0450(1994)033<0140:ASTMFM>2.0.CO;2.

__ J. Jmith, M. Doggett, M. Halbleib, and W. Gibson, 2006: High-resolution climate maps for the Pacific Basin Islands, 1971-2000. National Park Service Pacific West Regional Office Rep., 59 pp.

Dawdy, D. R., and W. B. Langbein, 1960: Mapping mean areal precipitation. Hydrol. Sci. J., 5, 16-23, https://doi.org/10.1080/ 02626666009493176.

Di Piazza, A., F. Lo Conti, L. V. Noto, F. Viola, and G. La Loggia, 2011: Comparative analysis of different techniques for spatial interpolation of rainfall data to create a serially complete monthly time series of precipitation for Sicily, Italy. Int. J. Appl. Earth Obs. Geoinf., 13, 396-408, https://doi.org/ 10.1016/j.jag.2011.01.005.

Dodson, R., and D. Marks, 1997: Daily air temperature interpolated at high spatial resolution over a large mountainous region. Climate Res., 8, 1-20, https://doi.org/10.3354/cr008001.

Frazier, A. G., T. W. Giambelluca, H. F. Diaz, and H. L. Needham, 2016: Comparison of geostatistical approaches to spatially interpolate month-year rainfall for the Hawaiian Islands. Int. J. Climatol., 36, 1459-1470, https://doi.org/ 10.1002/joc. 4437.

Garza, J. A., P. S. Chu, C. W. Norton, and T. A. Schroeder, 2012: Changes of the prevailing trade winds over the islands of Hawaii and the North Pacific. J. Geophys. Res., 117, D11109, https://doi.org/10.1029/2011JD016888.

Giambelluca, T. W., M. A. Nullet, and T. A. Schroeder, 1986: Rainfall atlas of Hawai'i. Rep. R76, Hawaii Division of Water and Land Development, Department of Land and Natural Resources, 267 pp.

, Q. Chen, A. G. Frazier, J. P. Price, Y. L. Chen, P. S. Chu, J. K. Eischeid, and D. M. Delparte, 2013: Online rainfall atlas of Hawai'i. Bull. Amer. Meteor. Soc., 94, 313-316, https://doi.org/ 10.1175/BAMS-D-11-00228.1.

—_, and Coauthors, 2014: Evapotranspiration of Hawai'i. Final Rep. submitted to the U.S. Army Corps of Engineers-Honolulu District and the Commission on Water Resource Management, 178 pp., http://evapotranspiration.geography.hawaii.edu/assets/ files/PDF/ET\%20Project\%20Final\%20Report.pdf.

Hattermann, F. F., M. Wattenbach, V. Krysanova, and F. Wechsung, 2005: Runoff simulations on the macroscale with the ecohydrological model SWIM in the Elbe catchmentValidation and uncertainty analysis. Hydrol. Processes, 19 , 693-714, https://doi.org/10.1002/hyp.5625.

Haylock, M. R., N. Hofstra, A. M. G. Klein Tank, E. J. Klok, P. D. Jones, and M. New, 2008: A European daily high-resolution gridded data set of surface temperature and precipitation for 1950-2006. J. Geophys. Res., 113, D20119, https://doi.org/ 10.1029/2008JD010201.

Hofstra, N., M. Haylock, M. New, P. Jones, and C. Frei, 2008: Comparison of six methods for the interpolation of daily, European climate data. J. Geophys. Res., D21110, https://doi.org/ 10.1029/2008JD010100.

Hunter, R. D., and R. K. Meentemeyer, 2005: Climatologically aided mapping of daily precipitation and temperature. J. Appl. Meteor., 44, 1501-1510, https://doi.org/10.1175/JAM2295.1.
Jeffrey, S. J., J. O. Carter, K. B. Moodie, and A. R. Beswick, 2001: Using spatial interpolation to construct a comprehensive archive of Australian climate data. Environ. Modell. Software, 16, 309-330, https://doi.org/10.1016/S1364-8152(01)00008-1.

Juvik, S. P., and J. O. Juvik, 1998: Atlas of Hawai'i. 3rd ed. S. P. Juvik and J. O. Juvik, Eds., University of Hawaii Press, $333 \mathrm{pp}$

Kodama, K., and G. M. Barnes, 1997: Heavy rain events over the south-facing slopes of Hawaii: Attendant conditions. Wea. Forecasting, 12, 347-367, https://doi.org/10.1175/1520-0434(1997) 012<0347:HREOTS $>2.0 . \mathrm{CO} ; 2$.

Leopold, L. B., 1949: The interactions of trade wind and sea breeze in Hawaii. J. Meteor., 6, 312-320, https://doi.org/ 10.1175/1520-0469(1949)006<0312:TIOTWA >2.0.CO;2.

Li, J., and A. D. Heap, 2008: A review of spatial interpolation methods for environmental scientists. Geoscience Australia Record 2008/23, 137 pp.

Longman, R. J., H. F. Diaz, and T. W. Giambelluca, 2015: Sustained increases in lower-tropospheric subsidence over the central tropical North Pacific drive a decline in high-elevation rainfall in Hawaii. J. Climate, 28, 8743-8759, https://doi.org/10.1175/ JCLI-D-15-0006.1.

, and Coauthors, 2018: Compilation of climate data from heterogeneous networks across the Hawaiian Islands. Sci. Data, 5, 180012, https://doi.org/10.1038/sdata.2018.12.

Mair, A., and A. Fares, 2011: Comparison of rainfall interpolation methods in a mountainous region of a tropical island. J. Hydrol. Eng., 16, 371-383, https://doi.org/10.1061/ (ASCE)HE.1943-5584.0000330.

Minder, J. R., P. W. Mote, and J. D. Lundquist, 2010: Surface temperature lapse rates over complex terrain: Lessons from the Cascade Mountains. J. Geophys. Res., 115, D14122, https:// doi.org/10.1029/2009JD013493.

New, M., M. Hulme, and P. Jones, 2000: Representing twentiethcentury space-time climate variability. Part II: Development of 1901-96 monthly grids of terrestrial surface climate. J. Climate, 13, 2217-2238, https://doi.org/10.1175/1520-0442(2000) $013<2217$ :RTCSTC $>2.0 . \mathrm{CO} ; 2$.

Newman, A. J., and Coauthors, 2015: Gridded ensemble precipitation and temperature estimates for the contiguous United States. J. Hydrometeor., 16, 2481-2500, https://doi.org/ 10.1175/JHM-D-15-0026.1.

M. P. Clark, R. J. Longman, and T. W. Giambelluca, 2019a: Methodological intercomparisons of station-based gridded meteorological products: Utility, limitations, and paths forward. J. Hydrometeor., 20, 531-547, https://doi.org/ 10.1175/JHM-D-18-0114.1.

, E. Gilleland, T. W. Giambelluca, and J. R. Arnold, 2019b: Use of daily station observations to produce highresolution gridded probabilistic precipitation and temperature time series for the Hawaiian Islands. J. Hydrometeor., 20, 509529, https://doi.org/10.1175/JHM-D-18-0113.1.

Reimann, C., P. Filzmoser, and R. G. Garrett, 2005: Background and threshold: Critical comparison of methods of determination. Sci. Total Environ., 346, 1-16, https://doi.org/ 10.1016/j.scitotenv.2004.11.023.

Sanderson, M., 1993: Prevailing Trade Winds: Climate and Weather in Hawaii. University of Hawaii Press, 127 pp.

Shen, S. S. P., P. Dzikowski, G. Li, and D. Griffith, 2001: Interpolation of 1961-97 daily temperature and precipitation data onto Alberta polygons of ecodistrict and soil landscapes of Canada. J. Appl. Meteor., 40, 2162-2177, https://doi.org/ 10.1175/1520-0450(2001)040<2162:IODTAP $>2.0$. CO 2 . 
Shepard, D., 1964: A two-dimensional interpolation for irregularlyspaced data function. ACM '68: Proceedings of the 1968 23rd ACM National Conference, ACM, 517-524.

Teegavarapu, R. S. V., and V. Chandramouli, 2005: Improved weighting methods, deterministic and stochastic data-driven models for estimation of missing precipitation records. $J$. $\mathrm{Hy}$ drol., 312, 191-206, https://doi.org/10.1016/j.jhydrol.2005.02.015.

Thornton, P. E., M. M. Thornton, B. W. Mayer, N. Wilhelmi, Y. Wei, R. Devarakonda, and R. Cook, 2012: Daymet: Daily surface weather on a $1 \mathrm{~km}$ grid for North America, 1980-2008. ORNL DAAC, accessed 31 May 2018, https://doi.org/10.3334/ ORNLDAAC/1219.

Tukey, T. W., 1977: Exploratory Data Analysis. Addison-Wesley, 688 pp.

Vicente-Serrano, S. M., and M. A. Saz-Sánchez, and J. M. Cuadrat, 2003: Comparative analysis of interpolation methods in the middle Ebro Valley (Spain): Application to annual precipitation and temperature. Climate Res., 24, 161-180, https://doi.org/ $10.3354 / \mathrm{cr} 024161$.

Wagner, P. D., P. Fiener, F. Wilken, S. Kumar, and K. Schneider, 2012: Comparison and evaluation of spatial interpolation schemes for daily rainfall in data scarce regions. J. Hydrol., 464-465, 388-400, https://doi.org/10.1016/ j.jhydrol.2012.07.026.

Webster, R., and M. A. Oliver, 2001: Geostatistics for Environmental Scientists. 2nd ed. John Wiley and Sons, $300 \mathrm{pp.}$

Wilks, D. S., 2006: Statistical Methods in the Atmospheric Sciences. 2nd ed. International Geophysics Series, Vol. 100, Academic Press, 648 pp.

Willmott, C. J., and S. M. Robeson, 1995: Climatologically aided interpolation (CAI) of terrestrial air temperature. Int. J. Climatol., 15, 221-229, https://doi.org/10.1002/joc.3370150207. 